\title{
Construction of prognostic microRNA signature for human invasive breast cancer by integrated analysis
}

This article was published in the following Dove Medical Press journal:

OncoTargets and Therapy

\author{
Wei Shi* \\ Fang Dong* \\ Yujia Jiang \\ Linlin Lu \\ Changwen Wang \\ Jie Tan \\ Wen Yang \\ Hui Guo \\ Jie Ming* \\ Tao Huang* \\ Department of Breast and Thyroid \\ Surgery, Union Hospital, Tongji \\ Medical College, Huazhong University \\ of Science and Technology, Wuhan \\ 430022, China \\ *These authors contributed equally \\ to this work
}

Background: Despite the advances in early detection and treatment methods, breast cancer still has a high mortality rate, even in those patients predicted to have a good prognosis. The purpose of this study is to identify a microRNA signature that could better predict prognosis in breast cancer and add new insights to the current classification criteria.

Materials and methods: We downloaded microRNA sequencing data along with corresponding clinicopathological data from The Cancer Genome Atlas (TCGA). Of 1,098 breast cancer patients identified, 253 patients with fully characterized microRNA profiles were selected for analysis. A three-microRNA signature was generated in the training set. Subsequently, the performance of the signature was confirmed in a validation set. After construction of the signature, we conducted additional experiments, including flow cytometry and the Cell Counting Kit- 8 assay, to illustrate the correlation of this microRNA signature with breast cancer cell cycle, apoptosis, and proliferation.

Results: Three microRNAs (hsa-mir-31, hsa-mir-16-2, and hsa-mir-484) were identified to be significantly and independently correlated with patient prognosis, and performed with good stability. Our results suggest that higher expression of $h s a-m i r-484$ indicated worse prognosis, while higher expression of $h s a-m i r-31$ and $h s a-m i r-16-2$ indicated better prognosis. Moreover, additional experiments confirmed that this microRNA signature was related to breast cancer cell cycle and proliferation.

Conclusion: Our results indicate a three-microRNA signature that can accurately predict the prognosis of breast cancer, especially in basal-like and hormone receptor-positive breast cancer subtypes. We recommend more aggressive therapy and more frequent follow-up for high-risk groups.

Keywords: microRNA, breast cancer, TCGA, prognosis

\section{Introduction}

Breast cancer is one of the most common malignancies among women, and despite the discovery of early detection methods and effective treatment therapies, it is still the second leading cause of cancer-related death in females. ${ }^{1}$ Breast cancer is a group of molecularly distinct neoplasms classified into four main subgroups based on their expression of estrogen receptor (ER), ${ }^{2}$ progesterone receptor (PR), and human epidermal growth factor receptor 2 (Her2). These subgroups require different treatment therapies and experience different clinical outcomes. However, even within the subgroups, there are different subsets of genetic and epigenetic abnormalities leading to different patient prognoses; ${ }^{3}$ thus, more research is needed to understand the mechanisms related to the prognosis within different breast cancer subgroups.
Correspondence: Tao Huang; Jie Ming Department of Breast and Thyroid Surgery, Union Hospital, Tongji Medical College, Huazhong University of Science and Technology, Wuhan 430022, China Tel +86 I38 07|I 2766;

$+8613995519049$

Fax +86 0278535 1622;

+8602785351622

Email huangtaowh@163.com;

mingjiewh@।26.com
OncoTargets and Therapy 2019:12 1979-2010

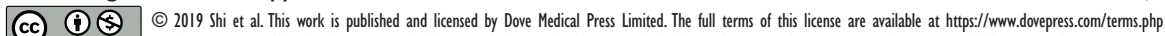

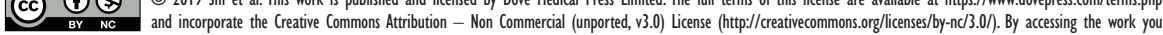
hereby accept the Terms. Non-commercial uses of the work are permitted without any further permision from Dove Medical Press Limited, provided the work is properly attributed. For permission for commercial use of this work, please see paragraphs 4.2 and 5 of our Terms (htpps://www.dovepress. com/terms.php). 
MicroRNAs are a class of endogenously expressed small, single-stranded, non-coding RNAs. Over the past decade, the aberrant expression of microRNAs has been increasingly reported in human cancers and has often been associated with diagnosis, ${ }^{4}$ prognosis, and response to clinical therapies. ${ }^{5}$ They are involved in the post-transcriptional regulation of gene expression via base pairing with target mRNAs (usually in the 3' untranslated region), causing degradation and translation repression of mRNAs. ${ }^{6}$ MicroRNAs are now widely regarded as the most powerful regulators of gene expression in complex cellular processes including cancer cell proliferation, metastasis, migration, and apoptosis. ${ }^{7}$ Of particular importance is the association with cancer cell proliferation and metastasis, as these are two hallmarks of malignancy and the leading causes of cancer-related death. ${ }^{5}$ In addition, many studies have shed light on tumor-targeting therapies using microRNAs as novel diagnostic and therapeutic tools. ${ }^{8,9}$

The Cancer Genome Atlas (TCGA) project provides researchers with a set of comprehensive tools that can be used to analyze clinical and genetic signatures of a variety of cancers including breast carcinoma. In this study, we retrieved breast carcinoma data from TCGA to construct a three-microRNA signature that can be used to predict the prognosis of breast cancer, and we verified the signature using both statistical and experimental methods.

\section{Materials and methods}

\section{TCGA breast invasive carcinoma data set}

The clinical information and expression levels from 1,158 microRNAs of 1,098 patients with breast as the primary cancer site were downloaded from TCGA (https://cancergenome. nih.gov/) on May 4, 2017. Patients were screened by the following criteria for inclusion: 1) the patients were female; 2) the patients had no preoperative treatment; 3) the patients' sample types were primary tumor; 4) the patients had fully characterized microRNA profiles; and 5) the percentage of necrosis in samples was $<40 \%$ on both the top and bottom slides. Patients who were alive but missing the date of last contact were excluded. A total of 253 breast invasive carcinoma patients were identified for further study according to the selection criteria. The total set was randomly separated into a training set (153 patients) and a validation set (100 patients).

\section{Construction and validation of the integrated microRNA signature}

The microRNA signature was constructed in the training set. A total of 1,158 microRNA expression levels were presented as reads per million (RPM) microRNA mapped data. Any microRNA expression level reads where microRNAs equaled 0 RPM in $>40 \%$ observations were excluded. After transformation into binary variables according to the median expression level, univariate Cox models were generated for preliminary screening of microRNAs that were significantly correlated with overall survival (OS). A cut-off $P$-value of $<0.05$ was used to filter out significant parameters. Clinical characteristics that were previously reported to be associated with prognosis, including age at diagnosis, N stage, T stage, metastasis, ER, PR, and Her2, were also similarly evaluated in the univariate Cox models. We then generated general multivariate stepwise Cox regression models to determine which of the significant microRNA identified by univariate proportional hazards regression was an independent predictor of prognosis. OS time was calculated from the date of the initial pathological diagnosis to the date of death.

The permutation test was used to evaluate the performance and randomness of the final multivariate model. Using the combination of patient OS time and vital status as a label, each patient was assigned a label and risk score under the microRNA scoring system. A random system was constructed by assigning labels while the risk score was kept consistent within each individual. The random system was tested for significance in predicting survival. If the model performed well, the random system was not a predictor of prognosis, and the area under the curve (AUC) of the receiver operating characteristics (ROC) curve would approach 0.5. We generated 1,000 random systems. A cut-off $P$-value of $<0.05$ was used to indicate a significant association between AUCs of the random system and the label system. We would conclude that the label system had no effect on outcome unless the calculated $P$-value was smaller than 0.05 . A validation set containing 100 patients was used to test the prognostic value of the microRNA signature. These analyses were performed using $\mathrm{R}$ software (version 3.3.2, https://www.r-project.org/).

\section{Bioinformatics analysis}

Targetscan7.1 (http://www.targetscan.org/vert 71/), DIANAmicroT, ${ }^{10}$ miRWalk, ${ }^{11}$ miRanda (http://www.microrna. org/microrna/home.do), PicTar (http://www.pictar.org/), and miRDB $^{12}$ were used to identify the target genes of three microRNAs. To increase accuracy, only target genes predicted by a minimum of three programs were retained for further analysis. Lists of target genes were submitted to DAVID Bioinformatics Resources 6.8 (https://david.ncifcrf.gov/) 
to annotate the biological functions of the candidate microRNAs. Subsequently, Gene Ontology (GO) function, Kyoto Encyclopedia of Genes and Genomes (KEGG) pathway enrichment analysis, ${ }^{13}$ and PANTHER ${ }^{\text {TM }}$ Version 11 analyses were conducted. Pathways with fold enrichment $>1.5$ and $P<0.05$ were considered to be of interest. ${ }^{14}$

\section{Cell lines and culturing method}

After evaluating qRT-PCR (data not shown) for the expression of the three microRNAs together with our statistical analysis results, we ultimately chose the cell line MDAMB-231 to continue further study. MDA-MB-231 was obtained from the American Type Culture Collection (Manassas, VA, USA), cultured according to the instructions, and used within 6 months after recovery from liquid nitrogen.

\section{Transfection, cell proliferation assay, and flow cytometry}

Cells were plated in six-well plates, transfected with microRNA mimic, microRNA inhibitor, and their corresponding negative controls using Lipofectamine ${ }^{\mathrm{TM}} 3000$ Transfection Reagent (Thermo Fisher Scientific, Waltham, MA, USA) following established protocols (transfection efficiency was at least $60 \%$ as confirmed by qRT-PCR; data not shown). All microRNA oligonucleotides were synthesized by RiboBio (Guangzhou, China) and quantification was performed with a stem-loop real-time PCR microRNA kit (RiboBio, Guangzhou, China). Transfected MDA-MB-231 was seeded at a density of $5 \times 10^{3}$ cells per well into 96 -well plates and incubated at $37^{\circ} \mathrm{C}$ for 72 hours. Cell viability was assessed using the Cell-Counting Kit-8 (CCK-8) assay (Dojindo, Kumamoto, Japan); absorbance values were determined at $450 \mathrm{~nm}$ using a microplate spectrophotometer. Flow cytometry was performed using propidium iodide (PI) staining solution (Chinese Academy of Sciences, Shanghai, China) and Annexin V: fluorescein isothiocyanate (FITC) Apoptosis Detection Kit I (BD Bioscience) following the instructions provided.

\section{Statistical analyses}

Apart from the above methods, other statistical analyses were performed using IBM SPSS Statistics version 22.0 (IBM Corp., Armonk, NY, USA). Survival analysis was conducted using the Kaplan-Meier method with the log-rank test. Means \pm SDs of continuous variables were calculated from at least three independent experiments. Student's $t$-test was used to compare groups and Pearson's chi-squared test to assess the correlation between variables. All statistical
Table I Univariate Cox analysis of I, I 58 microRNAs

\begin{tabular}{|l|l|l|l|}
\hline MicroRNA & $\boldsymbol{P}$-value & Coefficient & Type \\
\hline hsa-mir-3I & 0.008361862 & -0.625612446 & Protective \\
\hline hsa-mir-I6-2 & 0.007335068 & -0.629745321 & Protective \\
\hline hsa-mir-484 & 0.007238498 & 0.636249043 & Increased risk \\
\hline hsa-mir-877 & 0.00619359 & 0.652427525 & Increased risk \\
\hline hsa-let-7b & 0.00126726 & -0.781058038 & Protective \\
\hline hsa-mir-937 & 0.001580468 & 0.777204799 & Increased risk \\
\hline
\end{tabular}

tests were two-sided and a $P$-value $<0.05$ was considered statistically significant.

\section{Results \\ Construction of microRNA prognostic signature}

Six microRNAs were identified as prognostic markers after univariate Cox model screening (Table 1). Three microRNAs (hsa-mir-31, hsa-mir-16-2, and hsa-mir-484) were identified to be independently correlated with patient prognosis in multivariate Cox regression (Table 2); higher expression of $h s a-m i r-484$ indicated worse prognosis, while higher expression of hsa-mir-31 and hsa-mir-16-2 indicated improved prognosis. The $\beta$-coefficients (microRNA weight on OS) and status of every selected microRNA were used to calculate the risk score, as follows: risk score $=(0.494 *$ Status of hsa-mir-484) - (0.786* Status of hsa-mir-16-2) $(0.620 *$ Status of $h s a-m i r-31)$. The patients were assigned to the high-risk group if their risk score was greater than the median; otherwise, they were assigned to the low-risk group.

\section{Performance of microRNA signature}

The Kaplan-Meier and ROC analyses were applied to test the performance of the three-microRNA signature in the training set. The patients in the high-risk group had significantly worse OS than those in the low-risk group $(P<0.0001)$ (Figure 1A). The AUC of the signature was 0.683 (Figure 1B). These results confirmed that the threemicroRNA signature was powerful enough to divide breast cancer patients into high-risk and low-risk groups.

Table 2 Multivariate Cox analysis of I, I58 microRNAs

\begin{tabular}{|l|l|l|l|}
\hline MicroRNA & P-value & Coefficient & Type \\
\hline hsa-mir-3I & 0.011486 & -0.62045 & Protective \\
\hline hsa-mir-I6-2 & 0.001398 & -0.78621 & Protective \\
\hline hsa-mir-484 & 0.042246 & 0.493782 & Increased risk \\
\hline
\end{tabular}




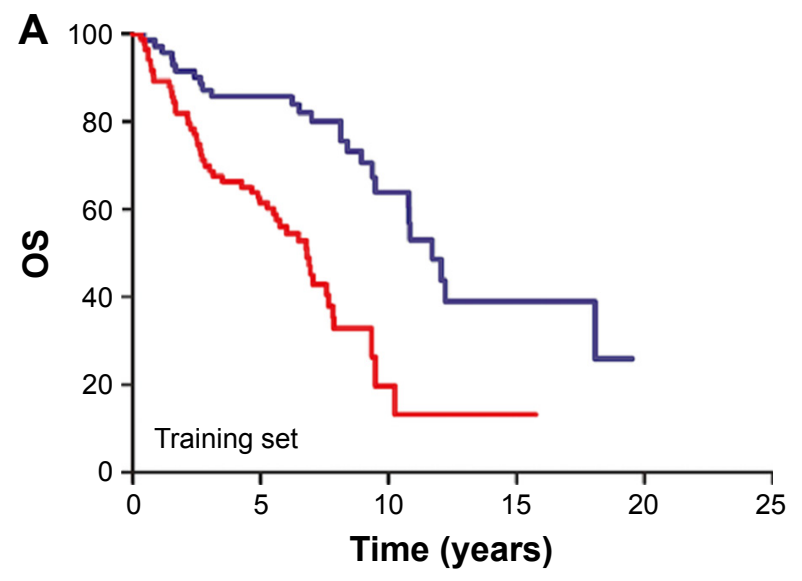

\begin{tabular}{|l|l|l|l|}
\hline & $\mathbf{N}$ & Median (year) & Log-rank $\boldsymbol{P}$ \\
\hline - Low risk & 70 & 11.707 & $P<0.0001$ \\
- High risk & 83 & 6.803 & \\
\hline
\end{tabular}

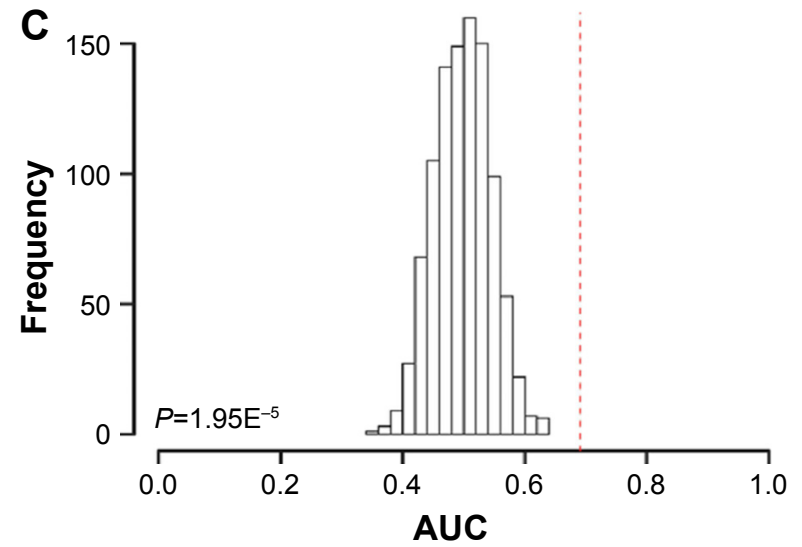

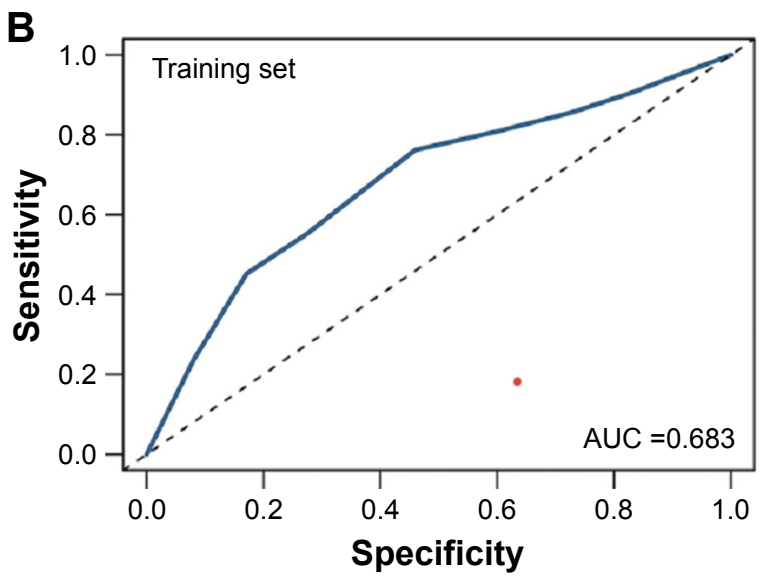

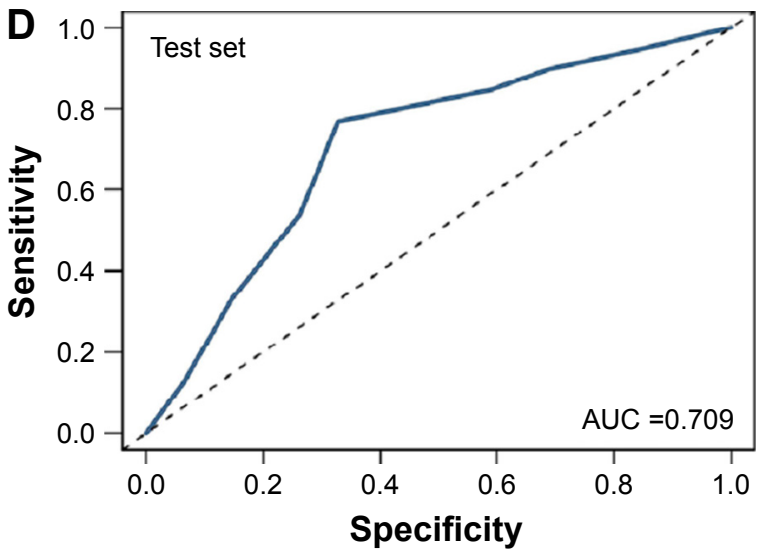

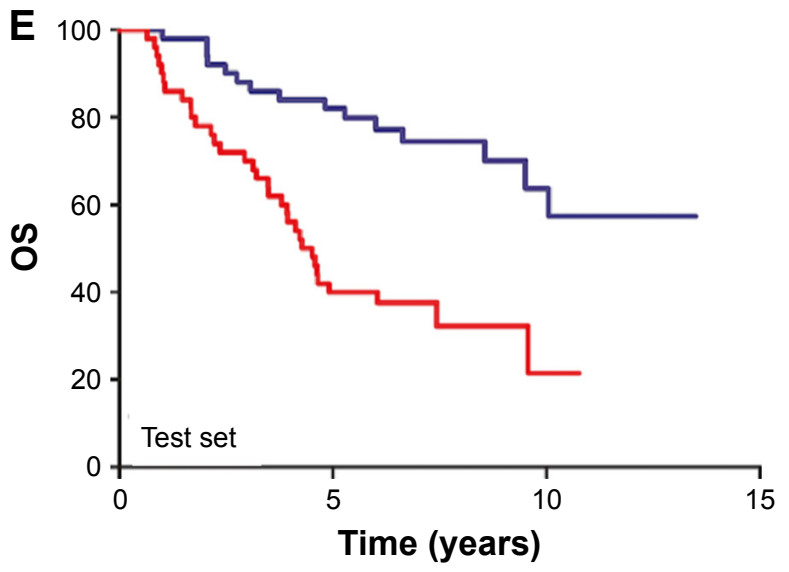

\begin{tabular}{|l|l|l|l|}
\hline & N & Median (year) & Log-rank $\boldsymbol{P}$ \\
\hline - Low risk & 50 & - & $P<0.0001$ \\
- High risk & 50 & 4.400 & \\
\hline
\end{tabular}

Figure I (A) Kaplan-Meier analysis of OS in the training set: OS rates between the high-risk group and low-risk group showed statistically significant differences using the log-rank test $(P<0.000 \mathrm{I})$; (B) ROC curve of the training set. (C) The permutation test found that the AUC of the random system showed great significance with high-risk and low-risk groups $(P=1.95 \mathrm{E}-05)$; (D) ROC curves of the validation set, $A \cup C=0.709$. (E) Kaplan-Meier analysis of OS in the test set: OS rates between the high-risk group and low-risk group showed statistically significant differences using the log-rank test $(P<0.000 \mathrm{I})$. All of these results suggest that our three-microRNA signature can be used as a better diagnostic marker to distinguish breast cancer patients into high-risk and low-risk groups.

Abbreviations: AUC, area under the curve; OS, overall survival; ROC, receiver operating characteristics. 
Next, we conducted a permutation test and leaveone-out cross-validation (LOO-CV) to test whether the three-microRNA signature was applicable to other breast cancer patients in the test set. ${ }^{15}$ The permutation test found that the AUC of the random system showed great significance with high-risk and low-risk groups $(P=1.95 \mathrm{E}-05)$ (Figure 1C). In addition, the LOO-CV AUC was 0.709 (Figure 1D) and the Kaplan-Meier curve indicated that the high-risk patients had significantly worse OS $(P<0.0001)$ (Figure 1E), which together validated the performance of the three-microRNA signature.

\section{Subgroup analysis}

After the construction and validation of the three-microRNA signature, we constructed Kaplan-Meier and ROC curves of OS in the total set (Figure 2). We then divided these patients into different subgroups according to their clinicopathological features to assess the performance of the three-microRNA signature in different groups.

First, the patients were separated into three groups based on their age at diagnosis ( $\leq 45$ years, $46-65$ years, and $>65$ years). In the $\leq 45$-year-old group, the AUC of the signature was 0.715 with a Kaplan-Meier curve $P$-value $<0.0001$ (Figure 3A and D). However, in the 46-65-year-old and $>65$-year-old groups, the AUCs were 0.57 and 0.561 , respectively, and the Kaplan-Meier curve $P$-values were 0.0798 and 0.422 , respectively (Figure 3B, C, E, and F).

Next, we grouped the patients based on their molecular subtype. For basal-like carcinoma patients, the AUC and
$P$-value were 0.755 and 0.003 , respectively (Figure $4 \mathrm{~A}$ and B). For luminal carcinoma patients, the AUC and $P$-value were 0.688 and $<0.0001$, respectively (Figure $4 \mathrm{C}$ and D). However, in the Her2-enriched subgroup, the AUC and $P$-value were 0.545 and 0.5532 , respectively (Figure $4 \mathrm{E}$ and F).

Finally, we analyzed the relationship between tumor stage and the microRNA signature. In the American Joint Committee on Cancer (AJCC) stage I and II group, the AUC and $P$-value were 0.724 and $<0.0001$, respectively (Figure 5A and $\mathrm{B}$ ); in the stage III and IV group, the AUC and $P$-value were 0.673 and $<0.013$, respectively (Figure 5C and D). There was no significant difference between these two groups.

\section{Clinical and pathological features and microRNA signature}

The clinical characteristics that were utilized to fit the univariate Cox model are shown in Table 3. In our study, age at diagnosis, ER status, PR status, Her2 status, and T stage were not associated with prognosis. $\mathrm{N}$ stage and metastasis had significant prognostic value, with $P$-values of 0.000 and 0.000 , respectively. After adjustment for $\mathrm{N}$ stage and metastasis, hsa-mir-31, hsa-mir-16-2, and hsa-mir-484 were all still independent prognostic factors (Table 4).

The correlation between patient clinicopathological characteristics and the microRNA signature is presented in Table 5. The microRNA signature was not associated with age at diagnosis, ER status, PR status, Her2 status, T stage, $\mathrm{N}$ stage or metastasis.
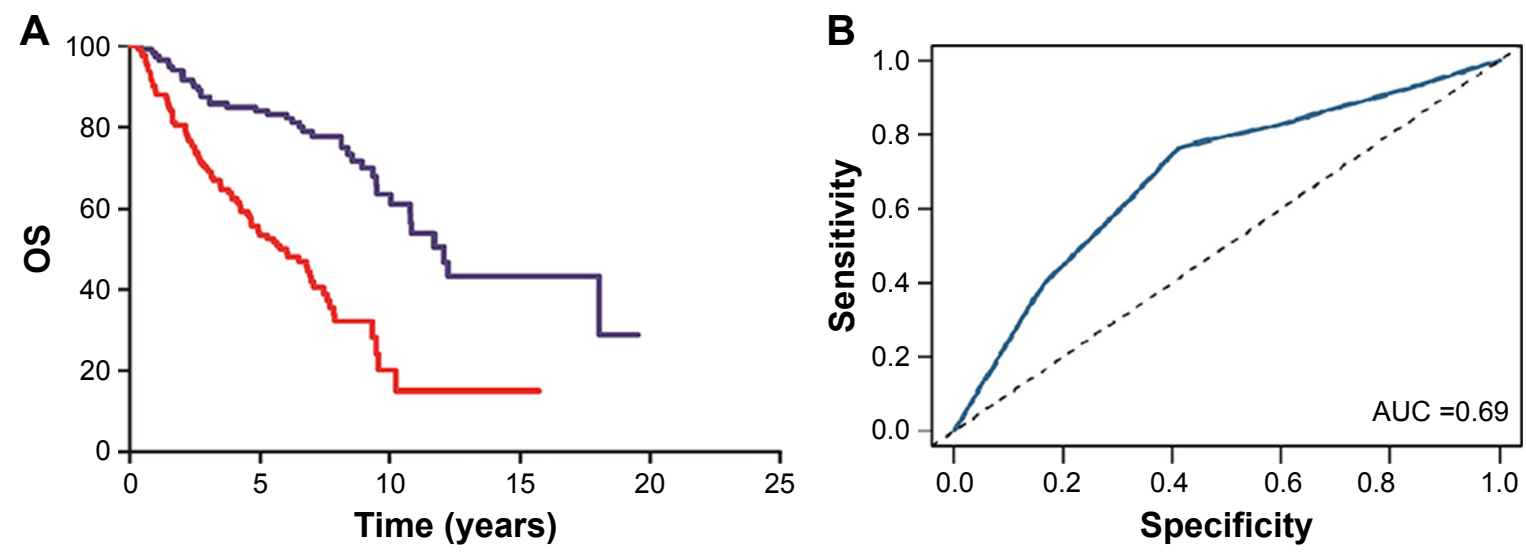

\begin{tabular}{|l|l|l|l|}
\hline & $\mathbf{N}$ & Median (year) & Log-rank $\boldsymbol{P}$ \\
\hline - Low risk & 120 & 12.049 & $P<0.0001$ \\
- High risk & 50 & 6.005 & \\
\hline
\end{tabular}

Figure 2 (A) Kaplan-Meier analysis of OS in the total set; (B) the ROC curve of the total set AUC was 0.69

Abbreviations: AUC, area under the curve; OS, overall survival; ROC, receiver operating characteristics. 

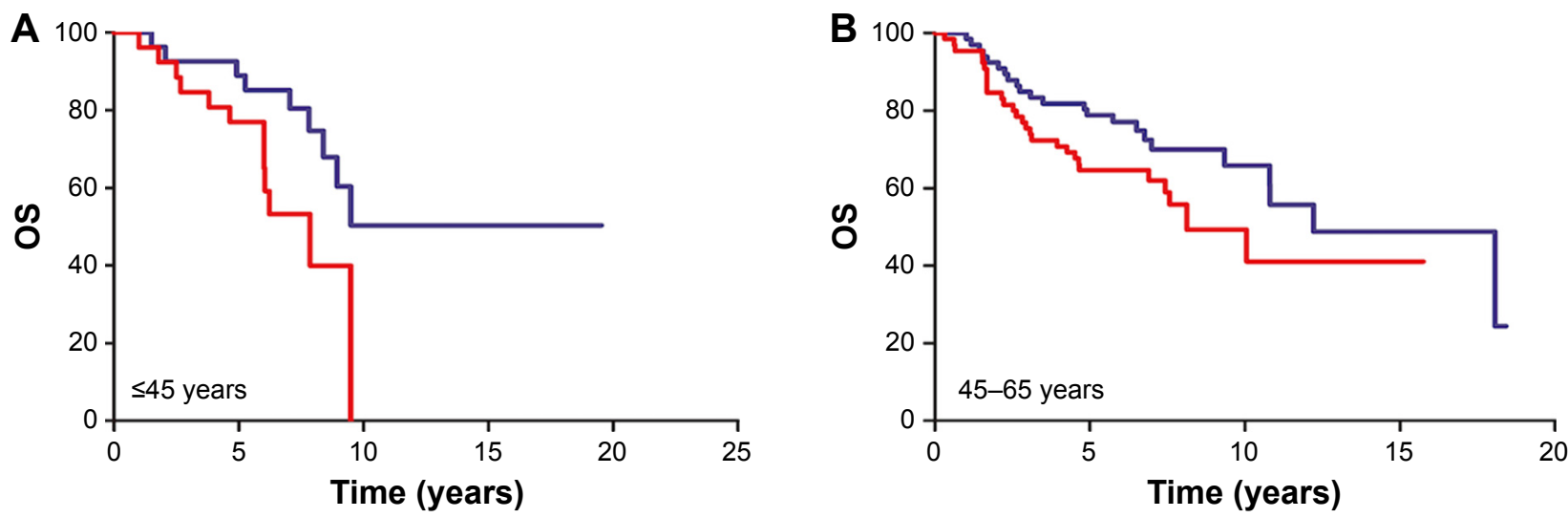

\begin{tabular}{|l|l|l|l|}
\hline & N & Median (year) & Log-rank $\boldsymbol{P}$ \\
\hline - Low risk & 27 & - & $P<0.0001$ \\
- High risk & 26 & 7.852 & \\
\hline
\end{tabular}

\begin{tabular}{|l|l|l|l|}
\hline & N & Median (year) & Log-rank $\boldsymbol{P}$ \\
\hline - Low risk & 66 & 12.21 & $P=0.0798$ \\
- High risk & 65 & 8.123 & \\
\hline
\end{tabular}
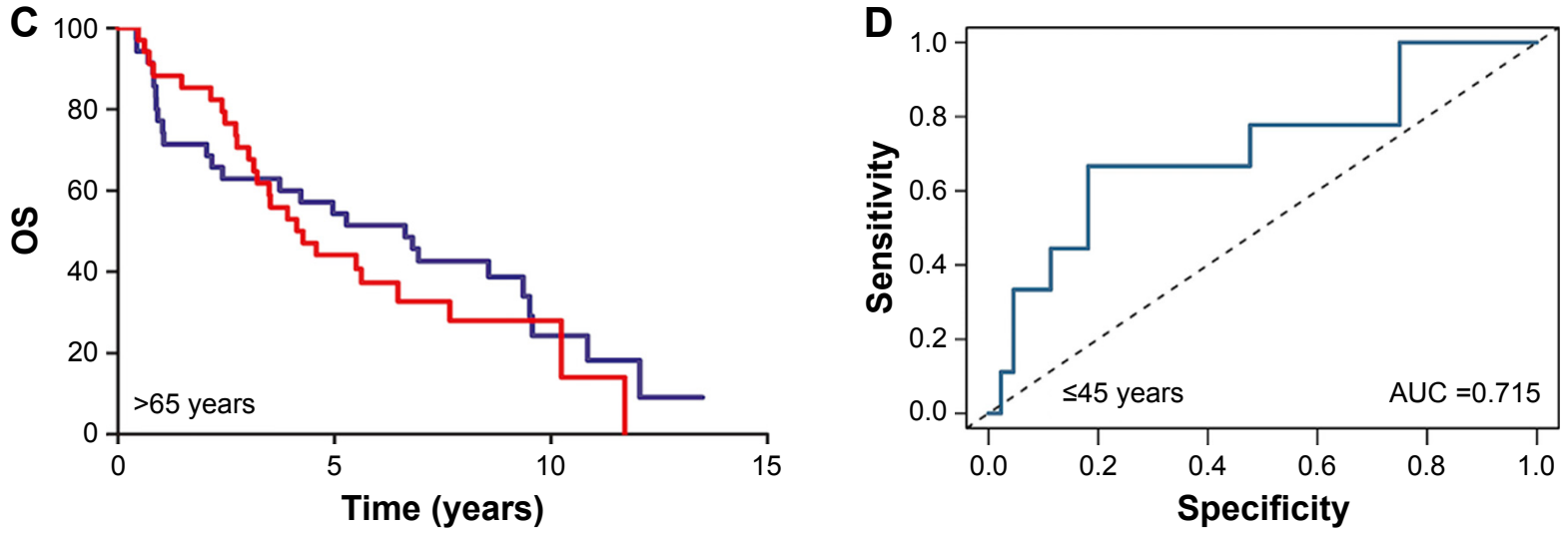

\begin{tabular}{|l|l|l|l|}
\hline & N & Median (year) & Log-rank $\boldsymbol{P}$ \\
\hline - Low risk & 35 & 6.636 & $P=0.422$ \\
- High risk & 34 & 4.207 & \\
\hline
\end{tabular}
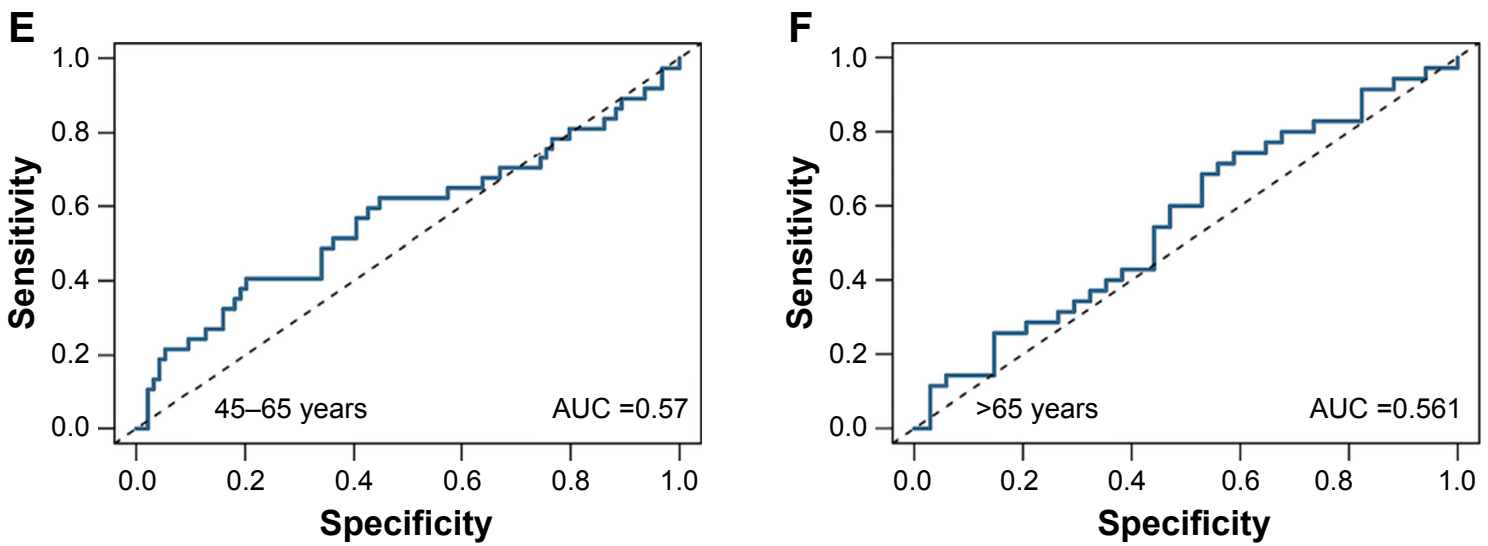

Figure 3 (A) Kaplan-Meier analysis of OS in the $\leq 45$-year age group: OS rates between the high-risk group and low-risk group showed statistically significant differences using the log-rank test $(P<0.000 \mathrm{I})$; (B) the ROC curve AUC was 0.715. (C) Kaplan-Meier analysis of OS in the 46-65-year age group: OS rates between the high-risk group and low-risk group showed no significant differences $(P=0.0798)$; (D) the ROC curve $A U C$ was 0.57 . (E) Kaplan-Meier analysis of $O S$ in the $>65$-year age group: OS rates between the high-risk group and low-risk group showed no significant differences $(P=0.561) ;(F)$ the ROC curve AUC was 0.422 . This signature performs better in younger patients ( $\leq 45$ years) than older patients ( $>65$ years).

Abbreviations: AUC, area under the curve; OS, overall survival; ROC, receiver operating characteristics. 


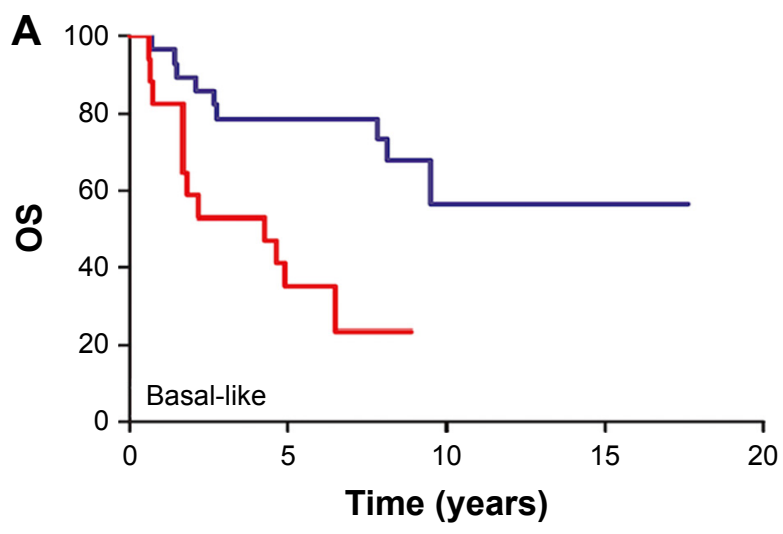

\begin{tabular}{|l|l|l|l|}
\hline & N & Median (year) & Log-rank $\boldsymbol{P}$ \\
\hline - Low risk & 28 & - & $P=0.003$ \\
- High risk & 17 & 4.263 & \\
\hline
\end{tabular}

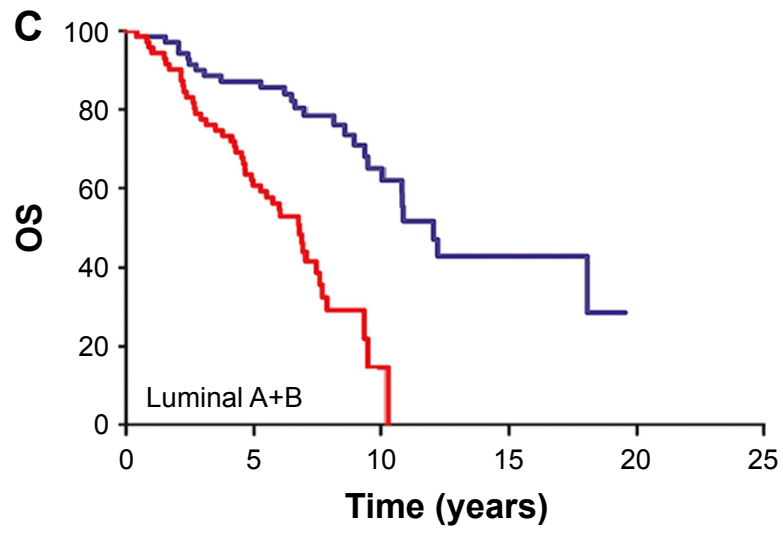

\begin{tabular}{|l|l|l|l|}
\hline & N & Median (year) & Log-rank $\boldsymbol{P}$ \\
\hline - Low risk & 70 & 12.049 & $P<0.0001$ \\
- High risk & 71 & 6.803 & \\
\hline
\end{tabular}

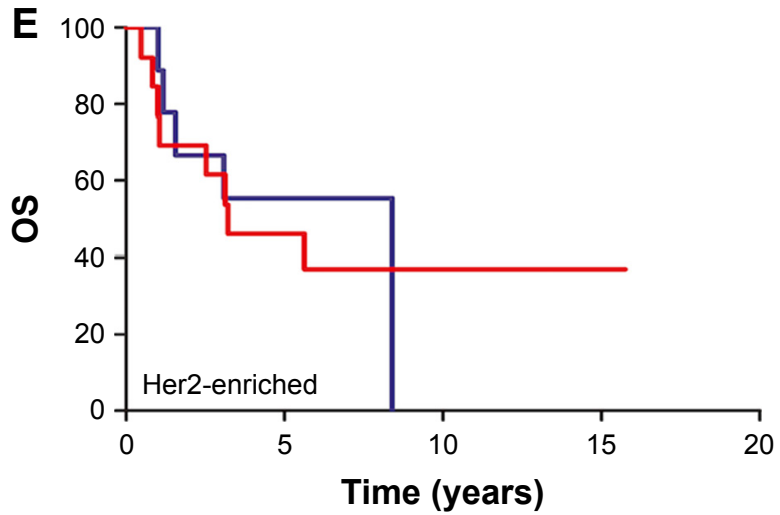

\begin{tabular}{|l|l|l|l|}
\hline & N & Median (year) & Log-rank $\boldsymbol{P}$ \\
\hline - Low risk & 9 & 8.392 & $P=0.5532$ \\
- High risk & 13 & 3.216 & \\
\hline
\end{tabular}

B
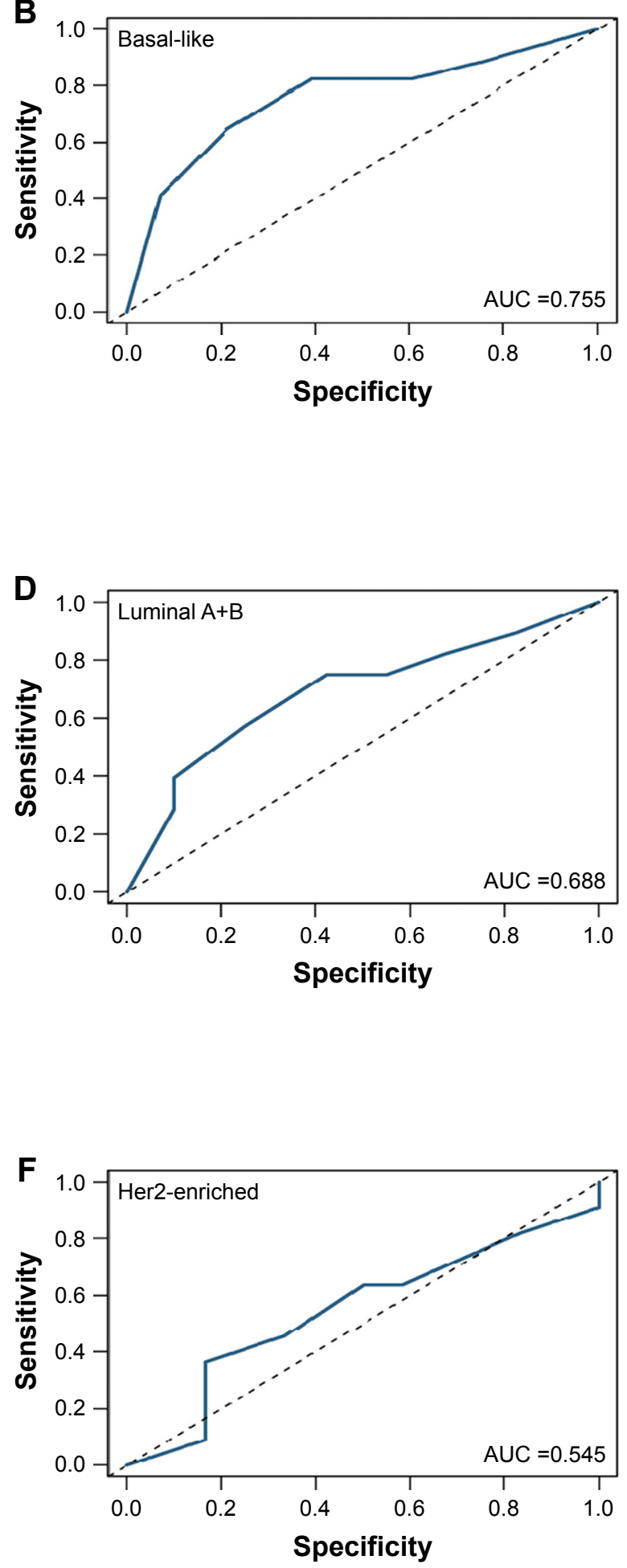

Figure 4 (A) Kaplan-Meier analysis of OS in the basal-like carcinoma group: OS rates between the high-risk group and low-risk group showed statistically significant differences using the log-rank test $(P=0.003)$; $(\mathbf{B})$ the ROC curve AUC was 0.755. (C) Kaplan-Meier analysis of OS in the luminal carcinoma group: OS rates between the high-risk group and low-risk group showed statistically significant differences using the log-rank test $(P<0.000$ I); (D) the ROC curve AUC was 0.688 . (E, F) Kaplan-Meier analysis of OS in the Her2-enriched subgroup showed no significant differences between the high-risk group and low-risk group; the AUC and P-value were 0.545 and 0.5532 , respectively. This signature showed better performance in basal-like and luminal patients than in Her2-enriched patients.

Abbreviations: AUC, area under the curve; OS, overall survival; ROC, receiver operating characteristics. 


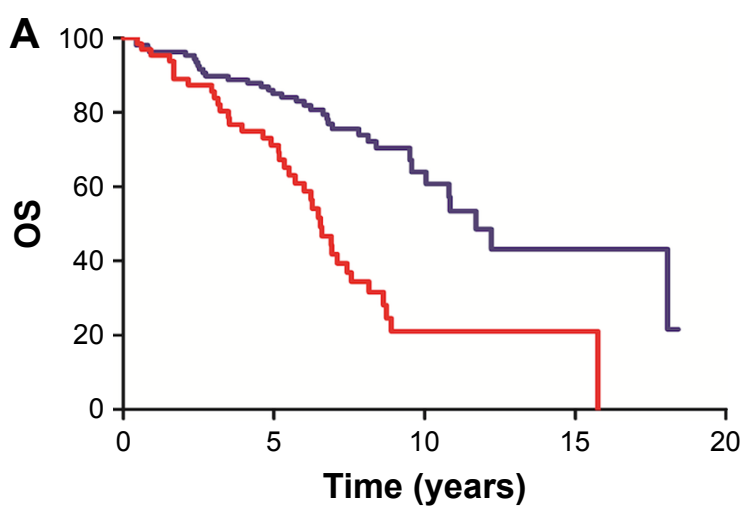

\begin{tabular}{|l|l|l|l|}
\hline & N & Median (year) & Log-rank $\boldsymbol{P}$ \\
\hline - Low risk & 107 & 11.707 & $P<0.0001$ \\
- High risk & 70 & 6.542 & \\
\hline
\end{tabular}

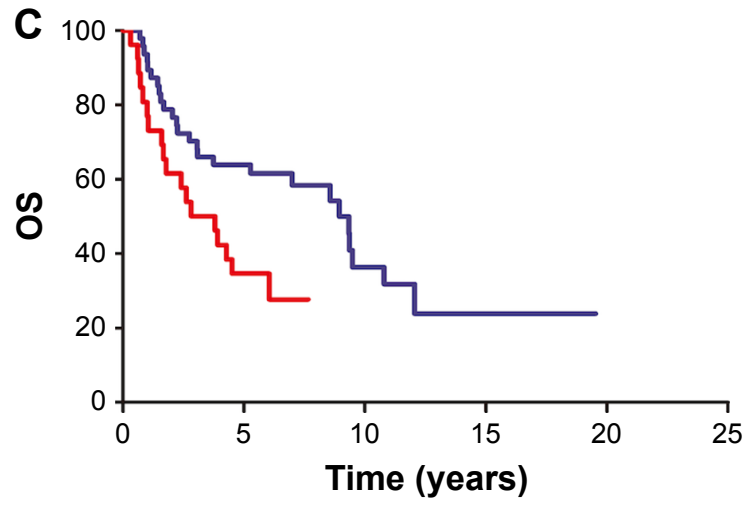

\begin{tabular}{|l|l|l|l|}
\hline & N & Median (year) & Log-rank $\boldsymbol{P}$ \\
\hline - Low risk & 47 & 8.937 & $P=0.013$ \\
- High risk & 26 & 3.315 & \\
\hline
\end{tabular}
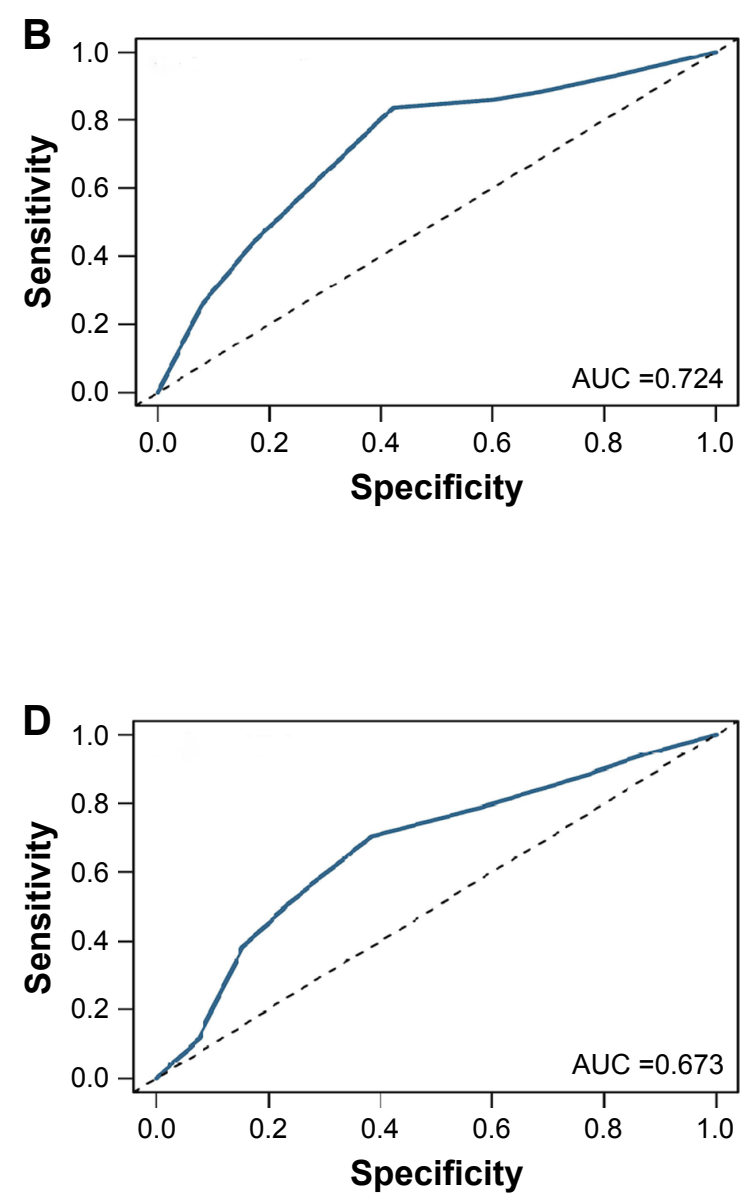

Figure 5 (A) Kaplan-Meier analysis of OS in stage I and II groups: OS rates between the high-risk group and low-risk group showed statistically significant differences $(P<0.000$ I); (B) the ROC curve AUC was 0.724. (C) Kaplan-Meier analysis of OS in stage III and IV groups: OS rates between the high-risk group and low-risk group showed statistically significant differences ( $P=0.0013$ ); (D) the ROC curve AUC was 0.673 . The performance of the signature was not associated with the $A J C C$ stage of the patients. Abbreviations: AJCC, American Joint Committee on Cancer; AUC, area under the curve; OS, overall survival; ROC, receiver operating characteristics.

GO annotation and KEGG pathway analysis of hsa-mir-3 I, hsa-mir-I6-2, and hsa-mir-484

Target genes of hsa-mir-16-2, hsa-mir-31, and hsa-mir-484, as predicted by five programs, are listed in Table 6 . There

Table 3 Univariate Cox analysis of clinicopathological parameters

\begin{tabular}{|c|c|c|c|c|}
\hline Variables & $\mathbf{n}$ & HR & $95 \% \mathrm{Cl}$ & $P$-value \\
\hline Age & 253 & I.448 & $0.905-2.317$ & 0.112 \\
\hline ER & 243 & 0.719 & $0.48 I-1.076$ & 0.108 \\
\hline PR & 243 & 0.715 & $0.49|-| .04 \mid$ & 0.080 \\
\hline Her2 & 232 & 1.165 & $0.693-1.958$ & 0.565 \\
\hline T stage & 250 & 1.106 & $0.892-|.37|$ & 0.361 \\
\hline $\mathrm{N}$ stage & 251 & I.47| & I.205-1.795 & 0.000 \\
\hline Metastasis & 238 & 3.260 & I.787-5.948 & 0.000 \\
\hline
\end{tabular}

Abbreviations: ER, estrogen receptor; Her2, human epidermal growth factor receptor 2; PR, progesterone receptor. were 254,149 , and 336 target genes predicted by at least three programs for hsa-mir-16-2, hsa-mir-31, and hsa-mir-484, respectively. GO annotation analysis included biological processes, cellular components, and molecular function, as shown in Table 7 (fold enrichment $>1.5, P<0.05$ ). These

Table 4 Multivariate Cox analysis of clinicopathological parameters and microRNAs

\begin{tabular}{|l|l|l|l|l|}
\hline Variables & $\mathbf{n}$ & $\mathbf{H R}$ & $\mathbf{9 5 \%} \mathbf{C l}$ & P-value \\
\hline N stage & 237 & 1.355 & $1.080-1.702$ & 0.009 \\
\hline Metastasis & 237 & 1.845 & $0.870-3.914$ & 0.110 \\
\hline hsa-mir-I6-2 & 237 & 0.556 & $0.379-0.817$ & 0.003 \\
\hline hsa-mir-484 & 237 & 1.560 & $1.043-2.332$ & 0.030 \\
\hline hsa-mir-3I & 237 & 0.486 & $0.333-0.7 I I$ & 0.000 \\
\hline hsa-mir-877 & 237 & $I .476$ & $0.968-2.25 I$ & $0.07 I$ \\
\hline hsa-mir-937 & 237 & 1.223 & $0.815-I .837$ & 0.331 \\
\hline hsa-let-7b & 237 & 0.670 & $0.437-1.027$ & 0.066 \\
\hline
\end{tabular}


Table 5 Correlation between microRNA expression level and clinical pathological parameters in breast cancer patients

\begin{tabular}{|c|c|c|c|c|}
\hline \multirow[t]{2}{*}{ Parameters } & \multirow{2}{*}{$\begin{array}{l}\text { Total } \\
\text { (n) }\end{array}$} & \multicolumn{2}{|c|}{ MicroRNA score } & \multirow[t]{2}{*}{$P$-value } \\
\hline & & $\begin{array}{l}\text { Low } \\
(n=\mid 20)\end{array}$ & $\begin{array}{l}\text { High } \\
(n=133)\end{array}$ & \\
\hline \multicolumn{4}{|l|}{ Age, years } & 0.791 \\
\hline$\leq 45$ & 53 & $26(21.7)$ & $27(20.3)$ & \\
\hline$>45$ & 200 & $94(78.3)$ & $106(79.7)$ & \\
\hline Missing (\%) & 0 & & & \\
\hline \multicolumn{4}{|l|}{ ER (\%) } & 0.723 \\
\hline Negative & 66 & $30(45.5)$ & $36(54.5)$ & \\
\hline Positive & 177 & $85(48.0)$ & $92(52.0)$ & \\
\hline Missing & 10 & & & \\
\hline \multicolumn{4}{|l|}{ PR (\%) } & 0.778 \\
\hline Negative & 91 & $42(46.2)$ & $49(53.8)$ & \\
\hline Positive & 152 & $73(48.0)$ & $79(52.0)$ & \\
\hline Missing & 10 & & & \\
\hline \multicolumn{4}{|c|}{ Her2 (FISH) (\%) } & 0.343 \\
\hline Negative & 197 & $96(48.7)$ & $101(51.3)$ & \\
\hline Positive & 35 & $14(40.0)$ & $21(60.0)$ & \\
\hline Missing & 21 & & & \\
\hline \multicolumn{4}{|l|}{ T stage (\%) } & 0.177 \\
\hline TI & 65 & $29(44.6)$ & $36(55.4)$ & \\
\hline $\mathrm{T} 2$ & 133 & $59(44.4)$ & $74(55.6)$ & \\
\hline T3 & 38 & $22(57.9)$ & $16(42.1)$ & \\
\hline T4 & 14 & $8(57.1)$ & $6(42.9)$ & \\
\hline Missing & 3 & & & \\
\hline \multicolumn{4}{|c|}{ Nodal stage (\%) } & 0.564 \\
\hline No & 114 & $53(46.5)$ & $61(53.5)$ & \\
\hline $\mathrm{NI}$ & 91 & $49(53.8)$ & $42(46.2)$ & \\
\hline N2 & 32 & $13(40.6)$ & $19(59.4)$ & \\
\hline N3 & 14 & $5(35.7)$ & $9(64.3)$ & \\
\hline Missing & 2 & & & \\
\hline \multicolumn{4}{|l|}{ Metastasis (\%) } & 0.947 \\
\hline Mo & 225 & $106(47.1)$ & $119(52.9)$ & \\
\hline MI & 13 & $6(46.2)$ & $7(53.8)$ & \\
\hline Missing & 15 & & & \\
\hline
\end{tabular}

Abbreviations: ER, estrogen receptor; FISH, fluorescence in situ hybridization Her2, human epidermal growth factor receptor 2; PR, progesterone receptor.

results indicate that these candidate targets are significantly related to biosynthesis, metabolic processes, DNA binding, and system development. Furthermore, they could be protein complex or transcription factor complex components. KEGG and PANTHER analyses indicate that the candidate targets were significantly enriched in several oncogenic signaling pathways, including Hippo $(P=0.0025)$, Wnt $(P=0.000852)$, epidermal growth factor $(\mathrm{EGF})$ receptor $(P=0.00712)$, fibroblast growth factor (FGF) $(P=0.000458)$, angiogenesis $(P=0.003092)$, adherens junction $(P=0.003865)$, and cytokine-cytokine receptor interaction $(P=0.001133)$, as shown in Table 8 . The three microRNAs are related to breast cancer cell cycle, viability, and apoptosis in vitro.

MDA-MB-231 cells were transfected according to the $\beta$-coefficient. One group was transfected with hsa-mir-484 inhibitor, hsa-mir-16-2 mimic, and hsa-mir-31 mimic (low-risk group), a second group was transfected with $h s a-$ mir-484 mimic, hsa-mir-16-2 inhibitor, and hsa-mir-31 inhibitor (high-risk group), and a final group was transfected with control sequences (negative control group). Cell cycle flow cytometry showed that the cell counts of S and G2/M phase were increased in both high-risk and low-risk groups compared to the negative control group (Figure 6A-D). The CCK-8 assay showed that cell viability of the highrisk group was significantly increased compared to the control group, while the viability of the low-risk group was decreased (Figure 6E). We then used an apoptosis assay to confirm whether cell apoptosis was increased in the experimental groups. Our results revealed that the apoptosis rate was $11.07 \%$ in the high-risk group (Figure 6F) and 30.49\% in low-risk group (Figure $6 \mathrm{G}$ ), while it was $12.01 \%$ in the control group (Figure 6H).

\section{Discussion}

Accumulating evidence has shown that microRNA deregulation plays a pivotal role in multiple cellular and biological processes, including cell proliferation and cell apoptosis, ${ }^{16-19}$ and targets a variety of pathways as oncogenes or tumor suppressors. Recently, microRNA-based anticancer therapies have been explored, either alone or in combination with other therapies. ${ }^{20,21}$ However, only a few articles have constructed a microRNA scoring system to predict the outcome of breast carcinoma. ${ }^{22,23}$ Here, we built a three-microRNA signature (hsa-mir-31, hsa-mir-484, and hsa-mir-16-2) that proved powerful enough to be an independent prognostic factor after rounds of statistical analysis.

According to our analysis, all three microRNAs target many cancer-related pathways, including the MAPK signaling pathway, ${ }^{24}$ Hippo signaling pathway, ${ }^{25}$ EGF receptor signaling pathway, ${ }^{26}$ and Wnt signaling pathway; ${ }^{27}$ some of these have been confirmed by previous studies. ${ }^{28}$ To be specific, hsa-mir-484 was found to be associated with poor prognosis in patients receiving gemcitabine treatment for breast cancer or sunitinib treatment for metastatic renal cell carcinoma and in ovarian cancer patients demonstrating chemosensitivity. ${ }^{28-30} \mathrm{In}$ addition, we found that circulating hsa-mir-484 is significantly differentially expressed, with decreased expression in the tumor tissue and increased expression in plasma compared to healthy volunteers. ${ }^{28,31-33}$ 
Table 6 Target genes of three microRNAs

\begin{tabular}{|c|c|c|}
\hline MicroRNA & Target gene & Annotation \\
\hline hsa-mir-3I & $N R 2 C 2$ & nuclear receptor subfamily 2 group $C$ member 2 \\
\hline hsa-mir-3I & MLXIP & MLX interacting protein \\
\hline hsa-mir-3I & STAU2 & staufen double-stranded RNA binding protein 2 \\
\hline hsa-mir-3I & ATF7IP & activating transcription factor 7 interacting protein \\
\hline hsa-mir-3I & PRKAA2 & protein kinase AMP-activated catalytic subunit alpha 2 \\
\hline hsa-mir-3I & ZNFI6 & zinc finger protein 16 \\
\hline hsa-mir-3I & RHBDL3 & rhomboid like 3 \\
\hline hsa-mir-3I & GPRC5A & G protein-coupled receptor class $C$ group 5 member $A$ \\
\hline hsa-mir-3I & ARIDIA & AT-rich interaction domain IA \\
\hline hsa-mir-3I & KHDRBS3 & KH RNA binding domain containing, signal transduction associated 3 \\
\hline hsa-mir-3I & UCN2 & urocortin 2 \\
\hline hsa-mir-3I & CTNND2 & catenin delta 2 \\
\hline hsa-mir-3I & $K L F / 3$ & Kruppel like factor 13 \\
\hline hsa-mir-3I & IQSEC2 & IQ motif and Sec7 domain 2 \\
\hline hsa-mir-3I & $R A B 6 B$ & RAB6B, member RAS oncogene family \\
\hline hsa-mir-3I & TFRC & transferrin receptor \\
\hline hsa-mir-3I & SLC24A3 & solute carrier family 24 member 3 \\
\hline hsa-mir-3I & KCNN3 & potassium calcium-activated channel subfamily $\mathrm{N}$ member 3 \\
\hline hsa-mir-3I & APBB2 & amyloid beta precursor protein binding family B member 2 \\
\hline hsa-mir-3I & TACC2 & transforming acidic coiled-coil containing protein 2 \\
\hline hsa-mir-3I & NDRG3 & NDRG family member 3 \\
\hline hsa-mir-3I & DICERI & dicer I, ribonuclease III \\
\hline hsa-mir-3I & SPREDI & sprouty related $\mathrm{EVHI}$ domain containing I \\
\hline hsa-mir-3I & NFAT5 & nuclear factor of activated T-cells 5 \\
\hline hsa-mir-3I & BAHDI & bromo adjacent homology domain containing I \\
\hline hsa-mir-3I & RTL9 & retrotransposon Gag like 9 \\
\hline hsa-mir-3I & KLF7 & Kruppel like factor 7 \\
\hline hsa-mir-3I & PRSS8 & protease, serine 8 \\
\hline hsa-mir-3I & PIK3C2A & phosphatidylinositol-4-phosphate 3-kinase catalytic subunit type 2 alpha \\
\hline hsa-mir-3I & FNDC5 & fibronectin type III domain containing 5 \\
\hline hsa-mir-3I & ZNHIT6 & zinc finger HIT-type containing 6 \\
\hline hsa-mir-3I & BTBDII & BTB domain containing II \\
\hline hsa-mir-3I & PHF8 & PHD finger protein 8 \\
\hline hsa-mir-3I & ZNF662 & zinc finger protein 662 \\
\hline hsa-mir-3I & TMPRSSIIF & transmembrane protease, serine IIF \\
\hline hsa-mir-3I & CCNC & cyclin C \\
\hline hsa-mir-3I & FZD4 & frizzled class receptor 4 \\
\hline hsa-mir-3I & SATB2 & SATB homeobox 2 \\
\hline hsa-mir-3I & SLC43A2 & solute carrier family 43 member 2 \\
\hline hsa-mir-3I & RSFI & remodeling and spacing factor I \\
\hline hsa-mir-3I & $R A P 2 B$ & RAP2B, member of RAS oncogene family \\
\hline hsa-mir-3I & FMNL3 & formin like 3 \\
\hline hsa-mir-3I & TM9SF4 & transmembrane 9 superfamily member 4 \\
\hline hsa-mir-3I & $P P P I R / 2 B$ & protein phosphatase I regulatory subunit I2B \\
\hline hsa-mir-3I & SLC39A/4 & solute carrier family 39 member 14 \\
\hline hsa-mir-3I & AKAP7 & A-kinase anchoring protein 7 \\
\hline hsa-mir-3I & $\mathrm{HOXCl} 3$ & homeobox $\mathrm{Cl} 3$ \\
\hline
\end{tabular}


Table 6 (Continued)

\begin{tabular}{|c|c|c|}
\hline MicroRNA & Target gene & Annotation \\
\hline hsa-mir-3I & $R A B / 4$ & RABI4, member RAS oncogene family \\
\hline hsa-mir-3I & PPBP & pro-platelet basic protein \\
\hline hsa-mir-3I & KIAA/429 & KIAAI429 \\
\hline hsa-mir-3I & KRT6C & keratin $6 \mathrm{C}$ \\
\hline hsa-mir-3I & FTMT & ferritin mitochondrial \\
\hline hsa-mir-3I & IGSFII & immunoglobulin superfamily member II \\
\hline hsa-mir-3I & RSBNI & round spermatid basic protein I \\
\hline hsa-mir-3I & SEPHSI & selenophosphate synthetase I \\
\hline hsa-mir-3I & PDZD2 & PDZ domain containing 2 \\
\hline hsa-mir-3I & TBXA2R & thromboxane $\mathrm{A} 2$ receptor \\
\hline hsa-mir-3I & $\angle B H$ & limb bud and heart development \\
\hline hsa-mir-3I & PRKCE & protein kinase $C$ epsilon \\
\hline hsa-mir-3I & $S H 2 D I A$ & SH2 domain containing IA \\
\hline hsa-mir-3I & GXYLTI & glucoside xylosyltransferase I \\
\hline hsa-mir-3I & LATS2 & large tumor suppressor kinase 2 \\
\hline hsa-mir-3I & CAMK2D & calcium/calmodulin dependent protein kinase II delta \\
\hline hsa-mir-3I & SYDE2 & synapse defective Rho GTPase homolog 2 \\
\hline hsa-mir-3I & KIAAI024 & KIAAI024 \\
\hline hsa-mir-3I & ELAVLI & ELAV like RNA binding protein I \\
\hline hsa-mir-3I & DCBLD2 & discoidin, CUB and LCCL domain containing 2 \\
\hline hsa-mir-3I & MAP4K5 & mitogen-activated protein kinase kinase kinase kinase 5 \\
\hline hsa-mir-3I & RGS4 & regulator of $\mathrm{G}$ protein signaling 4 \\
\hline hsa-mir-3I & MAPIB & microtubule associated protein IB \\
\hline hsa-mir-3I & PPPIR9A & protein phosphatase I regulatory subunit $9 \mathrm{~A}$ \\
\hline hsa-mir-3I & PAX9 & paired box 9 \\
\hline hsa-mir-3I & KANKI & $\mathrm{KN}$ motif and ankyrin repeat domains I \\
\hline hsa-mir-3I & WNKI & WNK lysine deficient protein kinase I \\
\hline hsa-mir-3I & WDR5 & WD repeat domain 5 \\
\hline hsa-mir-3I & SLCIA2 & solute carrier family I member 2 \\
\hline hsa-mir-3I & INSC & inscuteable homolog (Drosophila) \\
\hline hsa-mir-3I & NUPI53 & nucleoporin 153 \\
\hline hsa-mir-3I & MBOAT2 & membrane bound $\mathrm{O}$-acyltransferase domain containing 2 \\
\hline hsa-mir-3I & RNFI 44A & ring finger protein I44A \\
\hline hsa-mir-3I & MYO5A & myosin VA \\
\hline hsa-mir-3I & VPS26B & VPS26, retromer complex component B \\
\hline hsa-mir-3I & TNSI & tensin I \\
\hline hsa-mir-3I & NR5A2 & nuclear receptor subfamily 5 group A member 2 \\
\hline hsa-mir-3I & SLC6A6 & solute carrier family 6 member 6 \\
\hline hsa-mir-3I & PPP2R2A & protein phosphatase 2 regulatory subunit Balpha \\
\hline hsa-mir-3I & MGATI & mannosyl (alpha-I,3-)-glycoprotein beta-I,2-N-acetylglucosaminyltransferase \\
\hline hsa-mir-3I & RHOBTBI & Rho related BTB domain containing I \\
\hline hsa-mir-3I & IL34 & interleukin 34 \\
\hline hsa-mir-3I & ZNF384 & zinc finger protein 384 \\
\hline hsa-mir-3I & RASAI & RAS p2I protein activator I \\
\hline hsa-mir-3I & TMED IO & transmembrane $\mathrm{p} 24$ trafficking protein 10 \\
\hline hsa-mir-3I & ZFP30 & ZFP30 zinc finger protein \\
\hline hsa-mir-3I & PSMBII & proteasome subunit beta II \\
\hline
\end{tabular}


Table 6 (Continued)

\begin{tabular}{|c|c|c|}
\hline MicroRNA & Target gene & Annotation \\
\hline hsa-mir-3I & VAV3 & vav guanine nucleotide exchange factor 3 \\
\hline hsa-mir-3I & CRYBG3 & crystallin beta-gamma domain containing 3 \\
\hline hsa-mir-3I & PEX5 & peroxisomal biogenesis factor 5 \\
\hline hsa-mir-3I & RETREGI & reticulophagy regulator I \\
\hline hsa-mir-3I & PPP3CA & protein phosphatase 3 catalytic subunit alpha \\
\hline hsa-mir-3I & NUMB & NUMB, endocytic adaptor protein \\
\hline hsa-mir-3I & $P C$ & pyruvate carboxylase \\
\hline hsa-mir-3I & CEP85L & centrosomal protein 85 like \\
\hline hsa-mir-3I & YWHAE & tyrosine 3-monooxygenase/tryptophan 5-monooxygenase activation protein epsilon \\
\hline hsa-mir-3I & $\mathrm{BACH} 2$ & BTB domain and CNC homolog 2 \\
\hline hsa-mir-3I & EIF5 & eukaryotic translation initiation factor 5 \\
\hline hsa-mir-3I & VEZT & vezatin, adherens junctions transmembrane protein \\
\hline hsa-mir-3I & TACCI & transforming acidic coiled-coil containing protein I \\
\hline hsa-mir-3I & UBE2K & ubiquitin conjugating enzyme E2 K \\
\hline hsa-mir-3I & TM9SF3 & transmembrane 9 superfamily member 3 \\
\hline hsa-mir-3I & SGMSI & sphingomyelin synthase I \\
\hline hsa-mir-3I & ARHGEF2 & Rho/Rac guanine nucleotide exchange factor 2 \\
\hline hsa-mir-3I & COPS2 & COP9 signalosome subunit 2 \\
\hline hsa-mir-3I & SPARC & secreted protein acidic and cysteine rich \\
\hline hsa-mir-3I & CACNB2 & calcium voltage-gated channel auxiliary subunit beta 2 \\
\hline hsa-mir-3I & ZSWIM6 & zinc finger SWIM-type containing 6 \\
\hline hsa-mir-3I & CLCN3 & chloride voltage-gated channel 3 \\
\hline hsa-mir-3I & AHCYLI & adenosylhomocysteinase like I \\
\hline hsa-mir-3I & JAZFI & JAZF zinc finger I \\
\hline hsa-mir-3I & RIMS3 & regulating synaptic membrane exocytosis 3 \\
\hline hsa-mir-3I & TESK2 & testis-specific kinase 2 \\
\hline hsa-mir-3I & HIFIAN & hypoxia inducible factor I alpha subunit inhibitor \\
\hline hsa-mir-3I & KCTD20 & potassium channel tetramerization domain containing 20 \\
\hline hsa-mir-3I & STXI2 & syntaxin 12 \\
\hline hsa-mir-3I & OXSRI & oxidative stress responsive I \\
\hline hsa-mir-3I & CLOCK & clock circadian regulator \\
\hline hsa-mir-3I & EDNRB & endothelin receptor type B \\
\hline hsa-mir-3I & ATF6 & activating transcription factor 6 \\
\hline hsa-mir-3I & VAPB & VAMP associated protein B and C \\
\hline hsa-mir-3I & BICRA & BRD4 interacting chromatin remodeling complex associated protein \\
\hline hsa-mir-3I & VPS53 & VPS53, GARP complex subunit \\
\hline hsa-mir-3I & MBNL3 & muscleblind like splicing regulator 3 \\
\hline hsa-mir-3I & OSBP2 & oxysterol binding protein 2 \\
\hline hsa-mir-3I & MFAP3 & microfibrillar associated protein 3 \\
\hline hsa-mir-3I & CCNTI & cyclin TI \\
\hline hsa-mir-3I & ATP8AI & ATPase phospholipid transporting 8AI \\
\hline hsa-mir-3I & SIKEI & suppressor of IKBKE I \\
\hline hsa-mir-3I & HERPUD2 & HERPUD family member 2 \\
\hline hsa-mir-3I & PTGFRN & prostaglandin F2 receptor inhibitor \\
\hline hsa-mir-3I & EPCI & enhancer of polycomb homolog I \\
\hline hsa-mir-3I & GNAI3 & G protein subunit alpha 13 \\
\hline
\end{tabular}


Table 6 (Continued)

\begin{tabular}{|c|c|c|}
\hline MicroRNA & Target gene & Annotation \\
\hline hsa-mir-3I & $\mathrm{RPH} 3 \mathrm{~A}$ & rabphilin 3A \\
\hline hsa-mir-3I & MAP3KI & mitogen-activated protein kinase kinase kinase I \\
\hline hsa-mir-3I & $C B L$ & Cbl proto-oncogene \\
\hline hsa-mir-3I & JMJD8 & jumonji domain containing 8 \\
\hline hsa-mir-3I & STK40 & serine/threonine kinase 40 \\
\hline hsa-mir-3I & FZD3 & frizzled class receptor 3 \\
\hline hsa-mir-3I & PPP6C & protein phosphatase 6 catalytic subunit \\
\hline hsa-mir-3I & SUPTI6H & SPTI6 homolog, facilitates chromatin remodeling subunit \\
\hline hsa-mir-3I & EBF3 & early B-cell factor 3 \\
\hline hsa-mir-484 & PRRI4L & proline rich 14 like \\
\hline hsa-mir-484 & NFATC2 & nuclear factor of activated T-cells 2 \\
\hline hsa-mir-484 & PTPRF & protein tyrosine phosphatase, receptor type $\mathrm{F}$ \\
\hline hsa-mir-484 & HSPG2 & heparan sulfate proteoglycan 2 \\
\hline hsa-mir-484 & RSPO4 & R-spondin 4 \\
\hline hsa-mir-484 & PLCXD2 & phosphatidylinositol specific phospholipase $\mathrm{C} X$ domain containing 2 \\
\hline hsa-mir-484 & AGAP2 & ArfGAP with GTPase domain, ankyrin repeat and PH domain 2 \\
\hline hsa-mir-484 & DOLPPI & dolichyldiphosphatase I \\
\hline hsa-mir-484 & M6PR & mannose-6-phosphate receptor, cation dependent \\
\hline hsa-mir-484 & CMPKI & cytidine/uridine monophosphate kinase I \\
\hline hsa-mir-484 & SLC46A3 & solute carrier family 46 member 3 \\
\hline hsa-mir-484 & $A P I G I$ & adaptor related protein complex I gamma I subunit \\
\hline hsa-mir-484 & $T B C I D / 6$ & TBCI domain family member 16 \\
\hline hsa-mir-484 & THUMPD2 & THUMP domain containing 2 \\
\hline hsa-mir-484 & LDLRAD3 & low density lipoprotein receptor class A domain containing 3 \\
\hline hsa-mir-484 & FARPI & FERM, ARH/RhoGEF and pleckstrin domain protein I \\
\hline hsa-mir-484 & PREB & prolactin regulatory element binding \\
\hline hsa-mir-484 & DNDI & DND microRNA-mediated repression inhibitor I \\
\hline hsa-mir-484 & ANAPCII & anaphase promoting complex subunit II \\
\hline hsa-mir-484 & SEC24C & SEC24 homolog C, COPII coat complex component \\
\hline hsa-mir-484 & SLCIA4 & solute carrier family I member 4 \\
\hline hsa-mir-484 & UPF3A & UPF3 regulator of nonsense transcripts homolog $\mathrm{A}$ (yeast) \\
\hline hsa-mir-484 & $T B L I X$ & transducin beta like IX-linked \\
\hline hsa-mir-484 & CDSI & CDP-diacylglycerol synthase I \\
\hline hsa-mir-484 & TAGLN2 & transgelin 2 \\
\hline hsa-mir-484 & CD4 & CD4 molecule \\
\hline hsa-mir-484 & $H R$ & HR, lysine demethylase and nuclear receptor corepressor \\
\hline hsa-mir-484 & RPL26 & ribosomal protein L26 \\
\hline hsa-mir-484 & TNNII & troponin II, slow skeletal type \\
\hline hsa-mir-484 & IPO9 & importin 9 \\
\hline hsa-mir-484 & COG2 & component of oligomeric golgi complex 2 \\
\hline hsa-mir-484 & MAPIO & microtubule associated protein 10 \\
\hline hsa-mir-484 & SPOCDI & SPOC domain containing I \\
\hline hsa-mir-484 & HIC2 & HIC ZBTB transcriptional repressor 2 \\
\hline hsa-mir-484 & GUCD I & guanylyl cyclase domain containing I \\
\hline hsa-mir-484 & SGMS2 & sphingomyelin synthase 2 \\
\hline hsa-mir-484 & MCTPI & multiple C2 and transmembrane domain containing I \\
\hline hsa-mir-484 & ST6GALI & ST6 beta-galactoside alpha-2,6-sialyltransferase I \\
\hline
\end{tabular}


Table 6 (Continued)

\begin{tabular}{|c|c|c|}
\hline MicroRNA & Target gene & Annotation \\
\hline hsa-mir-484 & UBR2 & ubiquitin protein ligase E3 component n-recognin 2 \\
\hline hsa-mir-484 & NFIB & nuclear factor I B \\
\hline hsa-mir-484 & YTHDF3 & YTH N6-methyladenosine RNA binding protein 3 \\
\hline hsa-mir-484 & USP2 & ubiquitin specific peptidase 2 \\
\hline hsa-mir-484 & SEC3 IB & SEC3I homolog B, COPII coat complex component \\
\hline hsa-mir-484 & SH3PXD2A & $\mathrm{SH} 3$ and $\mathrm{PX}$ domains $2 \mathrm{~A}$ \\
\hline hsa-mir-484 & SPTLC2 & serine palmitoyltransferase long chain base subunit 2 \\
\hline hsa-mir-484 & GLGI & golgi glycoprotein I \\
\hline hsa-mir-484 & DCTN5 & dynactin subunit 5 \\
\hline hsa-mir-484 & SHANKI & SH3 and multiple ankyrin repeat domains I \\
\hline hsa-mir-484 & SIOOPBP & SI00P binding protein \\
\hline hsa-mir-484 & AMPD2 & adenosine monophosphate deaminase 2 \\
\hline hsa-mir-484 & NBPFI 4 & NBPF member 14 \\
\hline hsa-mir-484 & $\mathrm{DACH} 2$ & dachshund family transcription factor 2 \\
\hline hsa-mir-484 & ZNF34I & zinc finger protein 341 \\
\hline hsa-mir-484 & $V A P B$ & VAMP associated protein B and C \\
\hline hsa-mir-484 & TRIOBP & TRIO and F-actin binding protein \\
\hline hsa-mir-484 & CCR9 & C-C motif chemokine receptor 9 \\
\hline hsa-mir-484 & TACRI & tachykinin receptor I \\
\hline hsa-mir-484 & DCBLD2 & discoidin, CUB and LCCL domain containing 2 \\
\hline hsa-mir-484 & $K A L R N$ & kalirin, RhoGEF kinase \\
\hline hsa-mir-484 & OGDH & oxoglutarate dehydrogenase \\
\hline hsa-mir-484 & CYFIP2 & cytoplasmic FMRI interacting protein 2 \\
\hline hsa-mir-484 & CYP3A43 & cytochrome P450 family 3 subfamily A member 43 \\
\hline hsa-mir-484 & TRPSI & transcriptional repressor GATA binding I \\
\hline hsa-mir-484 & DCHSI & dachsous cadherin-related I \\
\hline hsa-mir-484 & TARBP2 & TARBP2, RISC loading complex RNA binding subunit \\
\hline hsa-mir-484 & NCAN & neurocan \\
\hline hsa-mir-484 & SERPINF2 & serpin family $\mathrm{F}$ member 2 \\
\hline hsa-mir-484 & EMC6 & ER membrane protein complex subunit 6 \\
\hline hsa-mir-484 & THPO & thrombopoietin \\
\hline hsa-mir-484 & TMEMI84A & transmembrane protein I84A \\
\hline hsa-mir-484 & TRMTIOB & tRNA methyltransferase IOB \\
\hline hsa-mir-484 & MLLT6 & MLLT6, PHD finger domain containing \\
\hline hsa-mir-484 & ZBTB47 & zinc finger and BTB domain containing 47 \\
\hline hsa-mir-484 & TCEANC2 & transcription elongation factor A N-terminal and central domain containing 2 \\
\hline hsa-mir-484 & TEX26I & testis expressed $26 \mathrm{I}$ \\
\hline hsa-mir-484 & CLOCK & clock circadian regulator \\
\hline hsa-mir-484 & NR6AI & nuclear receptor subfamily 6 group A member I \\
\hline hsa-mir-484 & MPRIP & myosin phosphatase Rho interacting protein \\
\hline hsa-mir-484 & TRIM66 & tripartite motif containing 66 \\
\hline hsa-mir-484 & $M L X I P$ & MLX interacting protein \\
\hline hsa-mir-484 & EIF4G2 & eukaryotic translation initiation factor 4 gamma 2 \\
\hline hsa-mir-484 & SERTAD I & SERTA domain containing I \\
\hline hsa-mir-484 & MBNL3 & muscleblind like splicing regulator 3 \\
\hline hsa-mir-484 & NEUROD4 & neuronal differentiation 4 \\
\hline hsa-mir-484 & DBNDD2 & dysbindin domain containing 2 \\
\hline
\end{tabular}


Table 6 (Continued)

\begin{tabular}{|c|c|c|}
\hline MicroRNA & Target gene & Annotation \\
\hline hsa-mir-484 & PAX5 & paired box 5 \\
\hline hsa-mir-484 & IPOII & importin II \\
\hline hsa-mir-484 & RFC5 & replication factor $C$ subunit 5 \\
\hline hsa-mir-484 & GRBIO & growth factor receptor bound protein 10 \\
\hline hsa-mir-484 & RNF40 & ring finger protein 40 \\
\hline hsa-mir-484 & SORBS2 & sorbin and $\mathrm{SH} 3$ domain containing 2 \\
\hline hsa-mir-484 & CYB56IDI & cytochrome b56I family member DI \\
\hline hsa-mir-484 & GAPVDI & GTPase activating protein and VPS9 domains I \\
\hline hsa-mir-484 & SLC4IA3 & solute carrier family $4 \mathrm{I}$ member 3 \\
\hline hsa-mir-484 & MAP2 & microtubule associated protein 2 \\
\hline hsa-mir-484 & POU2AFI & POU class 2 associating factor 1 \\
\hline hsa-mir-484 & CREM & cAMP responsive element modulator \\
\hline hsa-mir-484 & HHIPL2 & HHIP like 2 \\
\hline hsa-mir-484 & NAGA & alpha-N-acetylgalactosaminidase \\
\hline hsa-mir-484 & RTN3 & reticulon 3 \\
\hline hsa-mir-484 & NPNT & nephronectin \\
\hline hsa-mir-484 & IL6R & interleukin 6 receptor \\
\hline hsa-mir-484 & RFFL & ring finger and FYVE like domain containing E3 ubiquitin protein ligase \\
\hline hsa-mir-484 & SLC25A45 & solute carrier family 25 member 45 \\
\hline hsa-mir-484 & WASF3 & WAS protein family member 3 \\
\hline hsa-mir-484 & OPN4 & opsin 4 \\
\hline hsa-mir-484 & FAM46B & family with sequence similarity 46 member $B$ \\
\hline hsa-mir-484 & DBNL & drebrin like \\
\hline hsa-mir-484 & $A D D 2$ & adducin 2 \\
\hline hsa-mir-484 & DPYSL3 & dihydropyrimidinase like 3 \\
\hline hsa-mir-484 & VTIIA & vesicle transport through interaction with t-SNAREs IA \\
\hline hsa-mir-484 & CENPB & centromere protein B \\
\hline hsa-mir-484 & LRRC32 & leucine rich repeat containing 32 \\
\hline hsa-mir-484 & TOX4 & TOX high mobility group box family member 4 \\
\hline hsa-mir-484 & SNRNP200 & small nuclear ribonucleoprotein U5 subunit 200 \\
\hline hsa-mir-484 & PHFI9 & PHD finger protein 19 \\
\hline hsa-mir-484 & FBXO3I & F-box protein 31 \\
\hline hsa-mir-484 & ILI8BP & interleukin 18 binding protein \\
\hline hsa-mir-484 & SEMA4F & ssemaphorin $4 \mathrm{~F}$ \\
\hline hsa-mir-484 & GTDCl & glycosyltransferase like domain containing I \\
\hline hsa-mir-484 & COLQ & collagen like tail subunit of asymmetric acetylcholinesterase \\
\hline hsa-mir-484 & PRMI & protamine I \\
\hline hsa-mir-484 & LMAN2L & lectin, mannose binding 2 like \\
\hline hsa-mir-484 & LPL & lipoprotein lipase \\
\hline hsa-mir-484 & WWCI & $W W$ and $C 2$ domain containing $I$ \\
\hline hsa-mir-484 & MAPЗКII & mitogen-activated protein kinase kinase kinase II \\
\hline hsa-mir-484 & ANGPTI & angiopoietin I \\
\hline hsa-mir-484 & ZNF37A & zinc finger protein $37 \mathrm{~A}$ \\
\hline hsa-mir-484 & SGSM2 & small G protein signaling modulator 2 \\
\hline hsa-mir-484 & $E M X I$ & empty spiracles homeobox I \\
\hline hsa-mir-484 & LENG9 & leukocyte receptor cluster member 9 \\
\hline hsa-mir-484 & FBXOII & F-box protein II \\
\hline
\end{tabular}


Table 6 (Continued)

\begin{tabular}{|c|c|c|}
\hline MicroRNA & Target gene & Annotation \\
\hline hsa-mir-484 & HNFIA & HNFI homeobox $A$ \\
\hline hsa-mir-484 & SPATA2L & spermatogenesis associated 2 like \\
\hline hsa-mir-484 & TXNRD3 & thioredoxin reductase 3 \\
\hline hsa-mir-484 & CPSF4 & cleavage and polyadenylation specific factor 4 \\
\hline hsa-mir-484 & NEOI & neogenin I \\
\hline hsa-mir-484 & TCF7 & transcription factor 7 (T-cell specific, HMG-box) \\
\hline hsa-mir-484 & HOXA5 & homeobox A5 \\
\hline hsa-mir-484 & MTF2 & metal response element binding transcription factor 2 \\
\hline hsa-mir-484 & PIK3CD & phosphatidylinositol-4,5-bisphosphate 3-kinase catalytic subunit delta \\
\hline hsa-mir-484 & NCOA2 & nuclear receptor coactivator 2 \\
\hline hsa-mir-484 & RINI & Ras and Rab interactor I \\
\hline hsa-mir-484 & TRIM7I & tripartite motif containing 7I \\
\hline hsa-mir-484 & DDX3I & DEAD-box helicase 31 \\
\hline hsa-mir-484 & $A C B D 5$ & acyl-CoA binding domain containing 5 \\
\hline hsa-mir-484 & $A B R$ & active BCR-related \\
\hline hsa-mir-484 & GPR63 & G protein-coupled receptor 63 \\
\hline hsa-mir-484 & RARG & retinoic acid receptor gamma \\
\hline hsa-mir-484 & YAPI & Yes associated protein I \\
\hline hsa-mir-484 & RANBPI 7 & RAN binding protein 17 \\
\hline hsa-mir-484 & POLD4 & DNA polymerase delta 4 , accessory subunit \\
\hline hsa-mir-484 & FAM I 60B2 & family with sequence similarity 160 member B2 \\
\hline hsa-mir-484 & LYSMD I & LysM domain containing I \\
\hline hsa-mir-484 & PPARD & peroxisome proliferator activated receptor delta \\
\hline hsa-mir-484 & COL20AI & collagen type $X X$ alpha I chain \\
\hline hsa-mir-484 & SCP2 & sterol carrier protein 2 \\
\hline hsa-mir-484 & IL2ORB & interleukin 20 receptor subunit beta \\
\hline hsa-mir-484 & TMC8 & transmembrane channel like 8 \\
\hline hsa-mir-484 & SOX5 & SRY-box 5 \\
\hline hsa-mir-484 & MAPKAPKЗ & mitogen-activated protein kinase-activated protein kinase 3 \\
\hline hsa-mir-484 & ZNF667 & zinc finger protein 667 \\
\hline hsa-mir-484 & GRAMD IC & GRAM domain containing IC \\
\hline hsa-mir-484 & CRTC2 & CREB regulated transcription coactivator 2 \\
\hline hsa-mir-484 & SERFIB & small EDRK-rich factor IB \\
\hline hsa-mir-484 & FLVCR2 & feline leukemia virus subgroup $C$ cellular receptor family member 2 \\
\hline hsa-mir-484 & TRIM74 & tripartite motif containing 74 \\
\hline hsa-mir-484 & STAG3L3 & stromal antigen 3-like 3 (pseudogene) \\
\hline hsa-mir-484 & PKNOXI & PBX/knotted I homeobox I \\
\hline hsa-mir-484 & SOX2I & SRY-box 21 \\
\hline hsa-mir-484 & GLDN & gliomedin \\
\hline hsa-mir-484 & $\mathrm{HOXC8}$ & homeobox C8 \\
\hline hsa-mir-484 & FFAR2 & free fatty acid receptor 2 \\
\hline hsa-mir-484 & $S H 2 D / B$ & SH2 domain containing IB \\
\hline hsa-mir-484 & KDM4A & lysine demethylase $4 \mathrm{~A}$ \\
\hline hsa-mir-484 & $B C L 7 B$ & BCL tumor suppressor 7B \\
\hline hsa-mir-484 & PCDHI9 & protocadherin 19 \\
\hline hsa-mir-484 & SERFIA & small EDRK-rich factor IA \\
\hline hsa-mir-484 & EIF3J & eukaryotic translation initiation factor 3 subunit J \\
\hline
\end{tabular}


Table 6 (Continued)

\begin{tabular}{|c|c|c|}
\hline MicroRNA & Target gene & Annotation \\
\hline hsa-mir-484 & NGRN & neugrin, neurite outgrowth associated \\
\hline hsa-mir-484 & C3ORF62 & chromosome 3 open reading frame 62 \\
\hline hsa-mir-484 & MYCBP2 & MYC binding protein 2, E3 ubiquitin protein ligase \\
\hline hsa-mir-484 & PDEIIA & phosphodiesterase IIA \\
\hline hsa-mir-484 & AXIN2 & $\operatorname{axin} 2$ \\
\hline hsa-mir-484 & BRD9 & bromodomain containing 9 \\
\hline hsa-mir-484 & CLCN4 & chloride voltage-gated channel 4 \\
\hline hsa-mir-484 & FCFI & FCFI rRNA-processing protein \\
\hline hsa-mir-484 & SUSD5 & sushi domain containing 5 \\
\hline hsa-mir-484 & SP6 & Sp6 transcription factor \\
\hline hsa-mir-484 & LAMB3 & laminin subunit beta 3 \\
\hline hsa-mir-484 & MFRP & membrane frizzled-related protein \\
\hline hsa-mir-484 & THRSP & thyroid hormone responsive \\
\hline hsa-mir-484 & MED8 & mediator complex subunit 8 \\
\hline hsa-mir-484 & CCDCI42 & coiled-coil domain containing 142 \\
\hline hsa-mir-484 & FOXHI & forkhead box HI \\
\hline hsa-mir-484 & LGI4 & leucine rich repeat LGI family member 4 \\
\hline hsa-mir-484 & CHD8 & chromodomain helicase DNA binding protein 8 \\
\hline hsa-mir-484 & VLDLR & very low density lipoprotein receptor \\
\hline hsa-mir-484 & PGGHG & protein-glucosylgalactosylhydroxylysine glucosidase \\
\hline hsa-mir-484 & CSRNPI & cysteine and serine rich nuclear protein I \\
\hline hsa-mir-484 & N4BP2L2 & NEDD4 binding protein 2 like 2 \\
\hline hsa-mir-484 & CYB5B & cytochrome b5 type B \\
\hline hsa-mir-484 & PROM2 & prominin 2 \\
\hline hsa-mir-484 & CNTFR & ciliary neurotrophic factor receptor \\
\hline hsa-mir-484 & SEMA4D & semaphorin 4D \\
\hline hsa-mir-484 & DOK4 & docking protein 4 \\
\hline hsa-mir-484 & TOMM5 & translocase of outer mitochondrial membrane 5 \\
\hline hsa-mir-484 & DKK2 & dickkopf WNT signaling pathway inhibitor 2 \\
\hline hsa-mir-484 & $\mathrm{DACHI}$ & dachshund family transcription factor I \\
\hline hsa-mir-484 & CLEC6A & C-type lectin domain containing $6 \mathrm{~A}$ \\
\hline hsa-mir-484 & TTC39A & tetratricopeptide repeat domain $39 \mathrm{~A}$ \\
\hline hsa-mir-484 & TGFBRAPI & transforming growth factor beta receptor associated protein I \\
\hline hsa-mir-484 & VCP & valosin containing protein \\
\hline hsa-mir-484 & F2RL3 & F2R like thrombin/trypsin receptor 3 \\
\hline hsa-mir-484 & SNN & stannin \\
\hline hsa-mir-484 & ARLI5 & ADP ribosylation factor like GTPase I5 \\
\hline hsa-mir-484 & CNKSR3 & CNKSR family member 3 \\
\hline hsa-mir-484 & $|G B P|$ & immunoglobulin binding protein I \\
\hline hsa-mir-484 & TINF2 & TERFI interacting nuclear factor 2 \\
\hline hsa-mir-484 & SMYD4 & SET and MYND domain containing 4 \\
\hline hsa-mir-484 & $A C V R I B$ & activin A receptor type IB \\
\hline hsa-mir-484 & $I L 2 I R$ & interleukin 21 receptor \\
\hline hsa-mir-484 & DACT3 & disheveled binding antagonist of beta catenin 3 \\
\hline hsa-mir-484 & PDGFA & platelet derived growth factor subunit $\mathrm{A}$ \\
\hline hsa-mir-484 & NUP62 & nucleoporin 62 \\
\hline hsa-mir-484 & TAFIL & TATA-box binding protein associated factor I like \\
\hline
\end{tabular}


Table 6 (Continued)

\begin{tabular}{|c|c|c|}
\hline MicroRNA & Target gene & Annotation \\
\hline hsa-mir-484 & $\mathrm{CDHI}$ & cadherin I \\
\hline hsa-mir-484 & MRFAPILI & Morf4 family associated protein I like I \\
\hline hsa-mir-484 & NDUFA2 & NADH:ubiquinone oxidoreductase subunit A2 \\
\hline hsa-mir-484 & CCNLI & cyclin LI \\
\hline hsa-mir-484 & COL25AI & collagen type $X X V$ alpha I chain \\
\hline hsa-mir-484 & HERC3 & HECT and RLD domain containing E3 ubiquitin protein ligase 3 \\
\hline hsa-mir-484 & TRIM73 & tripartite motif containing 73 \\
\hline hsa-mir-484 & C9ORF62 & chromosome 9 open reading frame 62 \\
\hline hsa-mir-484 & SMUGI & single-strand-selective monofunctional uracil-DNA glycosylase I \\
\hline hsa-mir-484 & PYGO2 & Pygopus family PHD finger 2 \\
\hline hsa-mir-484 & PEX6 & peroxisomal biogenesis factor 6 \\
\hline hsa-mir-484 & CTAGEI & cutaneous T-cell lymphoma-associated antigen I \\
\hline hsa-mir-484 & IGLON5 & IgLON family member 5 \\
\hline hsa-mir-484 & ESR2 & estrogen receptor 2 \\
\hline hsa-mir-484 & LIN28B & lin-28 homolog B \\
\hline hsa-mir-484 & CTTNBP2NL & CTTNBP2 N-terminal like \\
\hline hsa-mir-484 & GJD4 & gap junction protein delta 4 \\
\hline hsa-mir-484 & SREBF2 & sterol regulatory element binding transcription factor 2 \\
\hline hsa-mir-484 & TSTD2 & thiosulfate sulfurtransferase like domain containing 2 \\
\hline hsa-mir-484 & GIGYFI & GRBI0 interacting GYF protein I \\
\hline hsa-mir-484 & RETREGI & reticulophagy regulator I \\
\hline hsa-mir-484 & SLC6AI & solute carrier family 6 member I \\
\hline hsa-mir-484 & GTF3C4 & general transcription factor IIIC subunit 4 \\
\hline hsa-mir-484 & TMIE & transmembrane inner ear \\
\hline hsa-mir-484 & HIPKI & homeodomain interacting protein kinase I \\
\hline hsa-mir-484 & HIVEP2 & human immunodeficiency virus type I enhancer binding protein 2 \\
\hline hsa-mir-484 & ANAPC7 & anaphase promoting complex subunit 7 \\
\hline hsa-mir-484 & $T H B D$ & thrombomodulin \\
\hline hsa-mir-484 & PTGER4 & prostaglandin E receptor 4 \\
\hline hsa-mir-484 & HOXAII & homeobox All \\
\hline hsa-mir-484 & RHOBTBI & Rho related BTB domain containing I \\
\hline hsa-mir-484 & IFNARI & interferon alpha and beta receptor subunit I \\
\hline hsa-mir-484 & JPTI & Jupiter microtubule associated homolog I \\
\hline hsa-mir-484 & FGFI & fibroblast growth factor I \\
\hline hsa-mir-484 & PTPRE & protein tyrosine phosphatase, receptor type E \\
\hline hsa-mir-484 & DPYSL2 & dihydropyrimidinase like 2 \\
\hline hsa-mir-484 & SORBSI & sorbin and $\mathrm{SH} 3$ domain containing I \\
\hline hsa-mir-484 & ZSWIM6 & zinc finger SWIM-type containing 6 \\
\hline hsa-mir-484 & NUP54 & nucleoporin 54 \\
\hline hsa-mir-484 & RIMS2 & regulating synaptic membrane exocytosis 2 \\
\hline hsa-mir-484 & STEAP3 & STEAP3 metalloreductase \\
\hline hsa-mir-484 & ABLIM2 & actin binding LIM protein family member 2 \\
\hline hsa-mir-484 & TNRC6C & trinucleotide repeat containing $6 \mathrm{C}$ \\
\hline hsa-mir-484 & TNFSF9 & TNF superfamily member 9 \\
\hline hsa-mir-484 & PIKFYVE & phosphoinositide kinase, FYVE-type zinc finger containing \\
\hline hsa-mir-484 & CPLX3 & complexin 3 \\
\hline hsa-mir-484 & PEA/5 & phosphoprotein enriched in astrocytes 15 \\
\hline
\end{tabular}


Table 6 (Continued)

\begin{tabular}{|c|c|c|}
\hline MicroRNA & Target gene & Annotation \\
\hline hsa-mir-484 & KIAAI549 & KIAAI549 \\
\hline hsa-mir-484 & SLC2OA2 & solute carrier family 20 member 2 \\
\hline hsa-mir-484 & CDK9 & cyclin dependent kinase 9 \\
\hline hsa-mir-484 & MAPKAPK2 & mitogen-activated protein kinase-activated protein kinase 2 \\
\hline hsa-mir-484 & CSFI & colony stimulating factor I \\
\hline hsa-mir-484 & PITPNA & phosphatidylinositol transfer protein alpha \\
\hline hsa-mir-484 & CSRNP2 & cysteine and serine rich nuclear protein 2 \\
\hline hsa-mir-484 & NFATC4 & nuclear factor of activated T-cells 4 \\
\hline hsa-mir-484 & AVL9 & AVL9 cell migration associated \\
\hline hsa-mir-484 & POTI & protection of telomeres I \\
\hline hsa-mir-484 & HLA-DOB & major histocompatibility complex, class II, DO beta \\
\hline hsa-mir-484 & DAGI & dystroglycan I \\
\hline hsa-mir-484 & STX5 & syntaxin 5 \\
\hline hsa-mir-484 & PRPF4B & pre-mRNA processing factor $4 \mathrm{~B}$ \\
\hline hsa-mir-484 & STRN & striatin \\
\hline hsa-mir-484 & CRTC3 & CREB regulated transcription coactivator 3 \\
\hline hsa-mir-484 & B3GNT9 & UDP-GlcNAc:betaGal beta-I,3-N-acetylglucosaminyltransferase 9 \\
\hline hsa-mir-484 & WFSI & wolframin ER transmembrane glycoprotein \\
\hline hsa-mir-484 & SLCI 7A9 & solute carrier family 17 member 9 \\
\hline hsa-mir-484 & TRIM33 & tripartite motif containing 33 \\
\hline hsa-mir-484 & $K C N J 14$ & potassium voltage-gated channel subfamily J member I4 \\
\hline hsa-mir-484 & TSPANI 7 & tetraspanin 17 \\
\hline hsa-mir-484 & ELMO2 & engulfment and cell motility 2 \\
\hline hsa-mir-484 & RAPGEF3 & Rap guanine nucleotide exchange factor 3 \\
\hline hsa-mir-484 & GTPBPIO & GTP binding protein 10 \\
\hline hsa-mir-484 & TSGAIO & testis specific 10 \\
\hline hsa-mir-484 & ZFYVEI & zinc finger FYVE-type containing I \\
\hline hsa-mir-484 & ADAM33 & ADAM metallopeptidase domain 33 \\
\hline hsa-mir-484 & MINKI & misshapen like kinase I \\
\hline hsa-mir-484 & NAFI & nuclear assembly factor I ribonucleoprotein \\
\hline hsa-mir-484 & VKORCI & vitamin $\mathrm{K}$ epoxide reductase complex subunit I \\
\hline hsa-mir-484 & TNR & tenascin R \\
\hline hsa-mir-484 & PNRCI & proline rich nuclear receptor coactivator I \\
\hline hsa-mir-484 & PRRT2 & proline rich transmembrane protein 2 \\
\hline hsa-mir-484 & SAMD4B & sterile alpha motif domain containing $4 \mathrm{~B}$ \\
\hline hsa-mir-484 & GOSR2 & golgi SNAP receptor complex member 2 \\
\hline hsa-mir-484 & TMEM/30 & transmembrane protein 130 \\
\hline hsa-mir-484 & FAM7IE2 & family with sequence similarity 71 member E2 \\
\hline hsa-mir-484 & DCLK3 & doublecortin like kinase 3 \\
\hline hsa-mir-484 & TMEM56 & transmembrane protein 56 \\
\hline hsa-mir-484 & TRATI & T-cell receptor associated transmembrane adaptor I \\
\hline hsa-mir-484 & ALPK3 & alpha kinase 3 \\
\hline hsa-mir-484 & GRPEL2 & GrpE like 2, mitochondrial \\
\hline hsa-mir-484 & RIPOR2 & RHO family interacting cell polarization regulator 2 \\
\hline hsa-mir-484 & MANIA2 & mannosidase alpha class IA member 2 \\
\hline hsa-mir-484 & STCl & stanniocalcin I \\
\hline hsa-mir-484 & ZMIZI & zinc finger MIZ-type containing I \\
\hline
\end{tabular}


Table 6 (Continued)

\begin{tabular}{|c|c|c|}
\hline MicroRNA & Target gene & Annotation \\
\hline hsa-mir-484 & TCHP & trichoplein keratin filament binding \\
\hline hsa-mir-484 & $B S D C I$ & BSD domain containing I \\
\hline hsa-mir-484 & TOX2 & TOX high mobility group box family member 2 \\
\hline hsa-mir-484 & FLOTI & flotillin I \\
\hline hsa-mir-484 & GRMI & glutamate metabotropic receptor I \\
\hline hsa-mir-484 & $B M P I$ & bone morphogenetic protein I \\
\hline hsa-mir-484 & WDR3 & WD repeat domain 3 \\
\hline hsa-mir-484 & $H K 2$ & hexokinase 2 \\
\hline hsa-mir-484 & PCDHA9 & protocadherin alpha 9 \\
\hline hsa-mir-484 & $X K R 9$ & XK related 9 \\
\hline hsa-mir-484 & CYB5RL & cytochrome b5 reductase like \\
\hline hsa-mir-484 & SUSD2 & sushi domain containing 2 \\
\hline hsa-mir-484 & RBM24 & RNA binding motif protein 24 \\
\hline hsa-mir-484 & $D L G 2$ & discs large MAGUK scaffold protein 2 \\
\hline hsa-mir-484 & DENND5A & DENN domain containing $5 \mathrm{~A}$ \\
\hline hsa-mir-484 & SAPI 30 & Sin $3 A$ associated protein 130 \\
\hline hsa-mir-16-2 & CCNB2 & cyclin B2 \\
\hline hsa-mir-16-2 & C22ORF29 & chromosome 22 open reading frame 29 \\
\hline hsa-mir-16-2 & CMTM7 & CKLF like MARVEL transmembrane domain containing 7 \\
\hline hsa-mir-16-2 & PRKGI & protein kinase, cGMP-dependent, type I \\
\hline hsa-mir-16-2 & PTER & phosphotriesterase related \\
\hline hsa-mir-16-2 & FAM49B & family with sequence similarity 49 member $B$ \\
\hline hsa-mir-16-2 & TSHZI & teashirt zinc finger homeobox I \\
\hline hsa-mir-16-2 & KIAA2022 & KIAA2022 \\
\hline hsa-mir-16-2 & PRDM 15 & PR/SET domain I5 \\
\hline hsa-mir-16-2 & KAT6A & lysine acetyltransferase $6 \mathrm{~A}$ \\
\hline hsa-mir-16-2 & KCTD $/ 5$ & potassium channel tetramerization domain containing I5 \\
\hline hsa-mir-16-2 & DIP2B & disco interacting protein 2 homolog B \\
\hline hsa-mir-16-2 & NEGRI & neuronal growth regulator I \\
\hline hsa-mir-16-2 & ACTNI & actinin alpha I \\
\hline hsa-mir-16-2 & ZBTB44 & zinc finger and BTB domain containing 44 \\
\hline hsa-mir-16-2 & ABTB2 & ankyrin repeat and BTB domain containing 2 \\
\hline hsa-mir-16-2 & CNRI & cannabinoid receptor I \\
\hline hsa-mir-16-2 & PCDHIIY & protocadherin II Y-linked \\
\hline hsa-mir-16-2 & $R A B I A$ & RABIA, member RAS oncogene family \\
\hline hsa-mir-16-2 & $R A B 6 B$ & RAB6B, member RAS oncogene family \\
\hline hsa-mir-16-2 & FAM I 35A & family with sequence similarity I 35 member $A$ \\
\hline hsa-mir-16-2 & ANKRD44 & ankyrin repeat domain 44 \\
\hline hsa-mir-16-2 & CFL2 & cofilin 2 \\
\hline hsa-mir-16-2 & PHLPPI & PH domain and leucine rich repeat protein phosphatase I \\
\hline hsa-mir-16-2 & STAG2 & stromal antigen 2 \\
\hline hsa-mir-16-2 & LMNBI & lamin BI \\
\hline hsa-mir-16-2 & SHANK2 & SH3 and multiple ankyrin repeat domains 2 \\
\hline hsa-mir-16-2 & TANC2 & tetratricopeptide repeat, ankyrin repeat and coiled-coil containing 2 \\
\hline hsa-mir-16-2 & MAP3K5 & mitogen-activated protein kinase kinase kinase 5 \\
\hline hsa-mir-16-2 & ELOA & elongin $\mathrm{A}$ \\
\hline hsa-mir-16-2 & SNRK & SNF related kinase \\
\hline
\end{tabular}


Table 6 (Continued)

\begin{tabular}{|c|c|c|}
\hline MicroRNA & Target gene & Annotation \\
\hline hsa-mir-16-2 & CLIC4 & chloride intracellular channel 4 \\
\hline hsa-mir-16-2 & $D G K B$ & diacylglycerol kinase beta \\
\hline hsa-mir-16-2 & TENMI & teneurin transmembrane protein I \\
\hline hsa-mir-16-2 & AMOTL2 & angiomotin like 2 \\
\hline hsa-mir-16-2 & PBRMI & polybromo I \\
\hline hsa-mir-16-2 & ANKRD $/ 2$ & ankyrin repeat domain 12 \\
\hline hsa-mir-16-2 & ZNF260 & zinc finger protein 260 \\
\hline hsa-mir-16-2 & GLS & glutaminase \\
\hline hsa-mir-16-2 & GRHL2 & grainyhead like transcription factor 2 \\
\hline hsa-mir-16-2 & KDM2A & lysine demethylase $2 \mathrm{~A}$ \\
\hline hsa-mir-16-2 & GDPDI & glycerophosphodiester phosphodiesterase domain containing I \\
\hline hsa-mir-16-2 & PTPNI2 & protein tyrosine phosphatase, non-receptor type 12 \\
\hline hsa-mir-16-2 & SBNOI & strawberry notch homolog I \\
\hline hsa-mir-16-2 & MPPED2 & metallophosphoesterase domain containing 2 \\
\hline hsa-mir-16-2 & ILI3RAI & interleukin I 3 receptor subunit alpha I \\
\hline hsa-mir-16-2 & CASP3 & caspase 3 \\
\hline hsa-mir-16-2 & SYVNI & synoviolin I \\
\hline hsa-mir-16-2 & USPI6 & ubiquitin specific peptidase 16 \\
\hline hsa-mir-I6-2 & FAMI20C & family with sequence similarity $\mathrm{I} 20 \mathrm{C}$ \\
\hline hsa-mir-16-2 & TMBIM4 & transmembrane BAX inhibitor motif containing 4 \\
\hline hsa-mir-16-2 & INTU & inturned planar cell polarity protein \\
\hline hsa-mir-16-2 & RAB6A & RAB6A, member RAS oncogene family \\
\hline hsa-mir-16-2 & PABPC4L & poly(A) binding protein cytoplasmic 4 like \\
\hline hsa-mir-I6-2 & CPEB2 & cytoplasmic polyadenylation element binding protein 2 \\
\hline hsa-mir-16-2 & $F A M / 26 B$ & family with sequence similarity 126 member $B$ \\
\hline hsa-mir-16-2 & CNTN4 & contactin 4 \\
\hline hsa-mir-16-2 & SEC24A & SEC24 homolog A, COPII coat complex component \\
\hline hsa-mir-16-2 & TLKI & tousled like kinase I \\
\hline hsa-mir-I6-2 & RNF6 & ring finger protein 6 \\
\hline hsa-mir-I6-2 & SPOPL & speckle type BTB/POZ protein like \\
\hline hsa-mir-16-2 & RAD2I & RAD2I cohesin complex component \\
\hline hsa-mir-16-2 & AMOTLI & angiomotin like I \\
\hline hsa-mir-16-2 & CHML & CHM like, Rab escort protein 2 \\
\hline hsa-mir-16-2 & RAPIA & RAPIA, member of RAS oncogene family \\
\hline hsa-mir-16-2 & CADM2 & cell adhesion molecule 2 \\
\hline hsa-mir-16-2 & $C D K I 7$ & cyclin dependent kinase 17 \\
\hline hsa-mir-16-2 & SGIPI & SH3 domain GRB2 like endophilin interacting protein I \\
\hline hsa-mir-16-2 & FRS2 & fibroblast growth factor receptor substrate 2 \\
\hline hsa-mir-16-2 & HSPA5 & heat shock protein family A (Hsp70) member 5 \\
\hline hsa-mir-16-2 & PAPD7 & poly(A) RNA polymerase D7, non-canonical \\
\hline hsa-mir-16-2 & TSHZ3 & teashirt zinc finger homeobox 3 \\
\hline hsa-mir-16-2 & PLAGLI & PLAG I like zinc finger I \\
\hline hsa-mir-16-2 & ACER3 & alkaline ceramidase 3 \\
\hline hsa-mir-16-2 & RCN2 & reticulocalbin 2 \\
\hline hsa-mir-16-2 & CYP26BI & cytochrome P450 family 26 subfamily B member I \\
\hline hsa-mir-16-2 & BTG3 & BTG anti-proliferation factor 3 \\
\hline hsa-mir-16-2 & ZNF770 & zinc finger protein 770 \\
\hline
\end{tabular}


Table 6 (Continued)

\begin{tabular}{|c|c|c|}
\hline MicroRNA & Target gene & Annotation \\
\hline hsa-mir-l6-2 & AEBP2 & AE binding protein 2 \\
\hline hsa-mir-16-2 & HNRNPLL & heterogeneous nuclear ribonucleoprotein L like \\
\hline hsa-mir-16-2 & FMNL2 & formin like 2 \\
\hline hsa-mir-16-2 & SP3 & Sp3 transcription factor \\
\hline hsa-mir-16-2 & FGL2 & fibrinogen like 2 \\
\hline hsa-mir-16-2 & PTPN 13 & protein tyrosine phosphatase, non-receptor type I3 \\
\hline hsa-mir-16-2 & $B C L / \mid B$ & B-cell CLL/lymphoma IIB \\
\hline hsa-mir-16-2 & LLGLI & LLGLI, scribble cell polarity complex component \\
\hline hsa-mir-16-2 & DPPIO & dipeptidyl peptidase like 10 \\
\hline hsa-mir-16-2 & ZSWIM6 & zinc finger SWIM-type containing 6 \\
\hline hsa-mir-16-2 & GRIA2 & glutamate ionotropic receptor AMPA type subunit 2 \\
\hline hsa-mir-16-2 & GALNTI & polypeptide $\mathrm{N}$-acetylgalactosaminyltransferase I \\
\hline hsa-mir-16-2 & PDEIOA & phosphodiesterase IOA \\
\hline hsa-mir-16-2 & HIFIA & hypoxia inducible factor I alpha subunit \\
\hline hsa-mir-16-2 & PRRXI & paired related homeobox I \\
\hline hsa-mir-16-2 & DSTYK & dual serine/threonine and tyrosine protein kinase \\
\hline hsa-mir-16-2 & KAT6B & lysine acetyltransferase 6B \\
\hline hsa-mir-16-2 & PCGF3 & polycomb group ring finger 3 \\
\hline hsa-mir-16-2 & $E M B$ & embigin \\
\hline hsa-mir-16-2 & TMLHE & trimethyllysine hydroxylase, epsilon \\
\hline hsa-mir-16-2 & TMEM I 6IB & transmembrane protein I6IB \\
\hline hsa-mir-16-2 & EIFIAX & eukaryotic translation initiation factor IA, X-linked \\
\hline hsa-mir-16-2 & ADCYAPI & adenylate cyclase activating polypeptide I \\
\hline hsa-mir-16-2 & NAT2 & $\mathrm{N}$-acetyltransferase 2 \\
\hline hsa-mir-16-2 & PEX5L & peroxisomal biogenesis factor 5 like \\
\hline hsa-mir-16-2 & $A G L$ & amylo-alpha-I, 6-glucosidase, 4-alpha-glucanotransferase \\
\hline hsa-mir-16-2 & COLIIAI & collagen type XI alpha I chain \\
\hline hsa-mir-16-2 & RBFOXI & RNA binding protein, fox-I homolog I \\
\hline hsa-mir-16-2 & CAV2 & caveolin 2 \\
\hline hsa-mir-16-2 & TDG & thymine DNA glycosylase \\
\hline hsa-mir-16-2 & IYD & iodotyrosine deiodinase \\
\hline hsa-mir-16-2 & FRK & fyn related Src family tyrosine kinase \\
\hline hsa-mir-16-2 & CLOCK & clock circadian regulator \\
\hline hsa-mir-16-2 & MEX3B & mex-3 RNA binding family member $B$ \\
\hline hsa-mir-16-2 & SATBI & SATB homeobox I \\
\hline hsa-mir-16-2 & DPYI9L4 & dpy- 19 like 4 (C. elegans) \\
\hline hsa-mir-16-2 & ZNF254 & zinc finger protein 254 \\
\hline hsa-mir-16-2 & CREBI & cAMP responsive element binding protein I \\
\hline hsa-mir-16-2 & ANKRD26 & ankyrin repeat domain 26 \\
\hline hsa-mir-16-2 & VDACI & voltage dependent anion channel I \\
\hline hsa-mir-16-2 & LRIGI & leucine rich repeats and immunoglobulin like domains I \\
\hline hsa-mir-16-2 & INPPI & inositol polyphosphate-I-phosphatase \\
\hline hsa-mir-16-2 & ZFP36 & ZFP36 ring finger protein \\
\hline hsa-mir-16-2 & HORMADI & HORMA domain containing I \\
\hline hsa-mir-16-2 & $T B C I D / 2$ & TBCI domain family member 12 \\
\hline hsa-mir-16-2 & CIORF2I & chromosome 1 open reading frame 2 I \\
\hline hsa-mir-16-2 & PAIP2 & poly (A) binding protein interacting protein 2 \\
\hline
\end{tabular}


Table 6 (Continued)

\begin{tabular}{|c|c|c|}
\hline MicroRNA & Target gene & Annotation \\
\hline hsa-mir-16-2 & HNRNPUL2 & heterogeneous nuclear ribonucleoprotein $U$ like 2 \\
\hline hsa-mir-16-2 & $S T X I 2$ & syntaxin 12 \\
\hline hsa-mir-16-2 & RORA & RAR related orphan receptor $A$ \\
\hline hsa-mir-16-2 & ТTC39B & tetratricopeptide repeat domain 39B \\
\hline hsa-mir-16-2 & ARAP2 & ArfGAP with RhoGAP domain, ankyrin repeat and PH domain 2 \\
\hline hsa-mir-16-2 & IGSFII & immunoglobulin superfamily member II \\
\hline hsa-mir-16-2 & MTF2 & metal response element binding transcription factor 2 \\
\hline hsa-mir-16-2 & CPEB3 & cytoplasmic polyadenylation element binding protein 3 \\
\hline hsa-mir-16-2 & ZNF615 & zinc finger protein 615 \\
\hline hsa-mir-16-2 & MIER3 & MIER family member 3 \\
\hline hsa-mir-16-2 & AHCTFI & AT-hook containing transcription factor I \\
\hline hsa-mir-16-2 & ZNF280D & zinc finger protein $280 \mathrm{D}$ \\
\hline hsa-mir-16-2 & UBE2V2 & ubiquitin conjugating enzyme E2 V2 \\
\hline hsa-mir-16-2 & SCN2A & sodium voltage-gated channel alpha subunit 2 \\
\hline hsa-mir-16-2 & PTARI & protein prenyltransferase alpha subunit repeat containing I \\
\hline hsa-mir-16-2 & EYA4 & EYA transcriptional coactivator and phosphatase 4 \\
\hline hsa-mir-16-2 & KRTAP4-5 & keratin associated protein $4-5$ \\
\hline hsa-mir-16-2 & LPARI & lysophosphatidic acid receptor I \\
\hline hsa-mir-16-2 & TAOK3 & TAO kinase 3 \\
\hline hsa-mir-16-2 & AFF2 & AF4/FMR2 family member 2 \\
\hline hsa-mir-16-2 & NYAP2 & neuronal tyrosine-phosphorylated phosphoinositide-3-kinase adaptor 2 \\
\hline hsa-mir-16-2 & DLLI & delta like canonical Notch ligand I \\
\hline hsa-mir-16-2 & RNF44 & ring finger protein 44 \\
\hline hsa-mir-16-2 & SEPSECS & Sep (O-phosphoserine) tRNA:Sec (selenocysteine) tRNA synthase \\
\hline hsa-mir-16-2 & CD226 & CD226 molecule \\
\hline hsa-mir-16-2 & HAND2 & heart and neural crest derivatives expressed 2 \\
\hline hsa-mir-16-2 & $S T / 3$ & STI3, Hsp70 interacting protein \\
\hline hsa-mir-16-2 & ICK & intestinal cell kinase \\
\hline hsa-mir-16-2 & ZNFII 7 & zinc finger protein 117 \\
\hline hsa-mir-l6-2 & OAZI & ornithine decarboxylase antizyme I \\
\hline hsa-mir-16-2 & ATPIIB & ATPase phospholipid transporting IIB (putative) \\
\hline hsa-mir-16-2 & HSDLI & hydroxysteroid dehydrogenase like I \\
\hline hsa-mir-16-2 & MME & membrane metalloendopeptidase \\
\hline hsa-mir-16-2 & PURA & purine rich element binding protein $\mathrm{A}$ \\
\hline hsa-mir-16-2 & RGS4 & regulator of G protein signaling 4 \\
\hline hsa-mir-16-2 & AUH & AU RNA binding methylglutaconyl-CoA hydratase \\
\hline hsa-mir-16-2 & SOATI & sterol O-acyltransferase I \\
\hline hsa-mir-16-2 & $T B X 18$ & T-box 18 \\
\hline hsa-mir-16-2 & HS6ST2 & heparan sulfate 6-O-sulfotransferase 2 \\
\hline hsa-mir-I 6-2 & ZNF569 & zinc finger protein 569 \\
\hline hsa-mir-16-2 & AZINI & antizyme inhibitor I \\
\hline hsa-mir-16-2 & IRF6 & interferon regulatory factor 6 \\
\hline hsa-mir-16-2 & RGS5 & regulator of G-protein signaling 5 \\
\hline hsa-mir-16-2 & ANKIBI & ankyrin repeat and IBR domain containing I \\
\hline hsa-mir-16-2 & TPP2 & tripeptidyl peptidase 2 \\
\hline hsa-mir-16-2 & SCARB2 & scavenger receptor class B member 2 \\
\hline hsa-mir-16-2 & KIAAII 07 & KIAAII 07 \\
\hline
\end{tabular}


Table 6 (Continued)

\begin{tabular}{|c|c|c|}
\hline MicroRNA & Target gene & Annotation \\
\hline hsa-mir-l6-2 & ZNF624 & zinc finger protein 624 \\
\hline hsa-mir-16-2 & BLOCIS2 & biogenesis of lysosomal organelles complex I subunit 2 \\
\hline hsa-mir-16-2 & $\mathrm{CHICl}$ & cysteine rich hydrophobic domain I \\
\hline hsa-mir-16-2 & TUBB2B & tubulin beta $2 \mathrm{~B}$ class IIb \\
\hline hsa-mir-16-2 & ZNF68I & zinc finger protein 681 \\
\hline hsa-mir-16-2 & ZNF236 & zinc finger protein 236 \\
\hline hsa-mir-16-2 & $B 2 M$ & beta-2-microglobulin \\
\hline hsa-mir-16-2 & PRKAAI & protein kinase AMP-activated catalytic subunit alpha I \\
\hline hsa-mir-16-2 & CUL2 & cullin 2 \\
\hline hsa-mir-16-2 & $N A B I$ & NGFI-A binding protein I \\
\hline hsa-mir-16-2 & CAMKID & calcium/calmodulin dependent protein kinase ID \\
\hline hsa-mir-16-2 & $S L C 2 A / 3$ & solute carrier family 2 member 13 \\
\hline hsa-mir-16-2 & FGF/4 & fibroblast growth factor 14 \\
\hline hsa-mir-16-2 & $K L$ & klotho \\
\hline hsa-mir-16-2 & HS2STI & heparan sulfate 2-O-sulfotransferase I \\
\hline hsa-mir-16-2 & ARID2 & AT-rich interaction domain 2 \\
\hline hsa-mir-16-2 & KIAA0408 & KIAA0408 \\
\hline hsa-mir-16-2 & STRBP & spermatid perinuclear RNA binding protein \\
\hline hsa-mir-16-2 & CLIP4 & CAP-Gly domain containing linker protein family member 4 \\
\hline hsa-mir-16-2 & DSC3 & desmocollin 3 \\
\hline hsa-mir-16-2 & SLC9C2 & solute carrier family 9 member C2 (putative) \\
\hline hsa-mir-16-2 & $\mathrm{RC} 3 \mathrm{HI}$ & ring finger and $\mathrm{CCCH}$-type domains I \\
\hline hsa-mir-16-2 & ATF3 & activating transcription factor 3 \\
\hline hsa-mir-16-2 & TAF5L & TATA-box binding protein associated factor 5 like \\
\hline hsa-mir-16-2 & HNRNPR & heterogeneous nuclear ribonucleoprotein $\mathrm{R}$ \\
\hline hsa-mir-16-2 & SSX2IP & SSX family member 2 interacting protein \\
\hline hsa-mir-16-2 & RAI2 & retinoic acid induced 2 \\
\hline hsa-mir-16-2 & RPS6KA3 & ribosomal protein $\mathrm{S} 6$ kinase $\mathrm{A} 3$ \\
\hline hsa-mir-16-2 & CYBB & cytochrome b- 245 beta chain \\
\hline hsa-mir-16-2 & $N K R F$ & NFKB repressing factor \\
\hline hsa-mir-16-2 & ARHGEF6 & Rac/Cdc42 guanine nucleotide exchange factor 6 \\
\hline hsa-mir-16-2 & ARFGEF2 & ADP ribosylation factor guanine nucleotide exchange factor 2 \\
\hline hsa-mir-16-2 & USP25 & ubiquitin specific peptidase 25 \\
\hline hsa-mir-16-2 & UBE2E2 & ubiquitin conjugating enzyme E2 E2 \\
\hline hsa-mir-16-2 & UBPI & upstream binding protein I (LBP-Ia) \\
\hline hsa-mir-16-2 & ZNF5 I 2 & zinc finger protein 512 \\
\hline hsa-mir-16-2 & STRN & striatin \\
\hline hsa-mir-16-2 & $B C L / I A$ & B-cell CLL/lymphoma IIA \\
\hline hsa-mir-16-2 & MAP3K2 & mitogen-activated protein kinase kinase kinase 2 \\
\hline hsa-mir-16-2 & GSTCD & glutathione S-transferase C-terminal domain containing \\
\hline hsa-mir-16-2 & TRPC3 & transient receptor potential cation channel subfamily $\mathrm{C}$ member 3 \\
\hline hsa-mir-16-2 & RAPGEF2 & Rap guanine nucleotide exchange factor 2 \\
\hline hsa-mir-16-2 & CLCN3 & chloride voltage-gated channel 3 \\
\hline hsa-mir-16-2 & $\mathrm{CDH} / 2$ & cadherin 12 \\
\hline hsa-mir-16-2 & DNAJC2I & DnaJ heat shock protein family (Hsp40) member C2I \\
\hline hsa-mir-16-2 & SNXI8 & sorting nexin 18 \\
\hline hsa-mir-I6-2 & ZBTB38 & zinc finger and BTB domain containing 38 \\
\hline
\end{tabular}


Table 6 (Continued)

\begin{tabular}{|c|c|c|}
\hline MicroRNA & Target gene & Annotation \\
\hline hsa-mir-16-2 & CCDC50 & coiled-coil domain containing 50 \\
\hline hsa-mir-16-2 & RBPJ & recombination signal binding protein for immunoglobulin kappa J region \\
\hline hsa-mir-16-2 & USP46 & ubiquitin specific peptidase 46 \\
\hline hsa-mir-16-2 & MOBIB & MOB kinase activator IB \\
\hline hsa-mir-16-2 & PARMI & prostate androgen-regulated mucin-like protein I \\
\hline hsa-mir-16-2 & CNKSR3 & CNKSR family member 3 \\
\hline hsa-mir-l6-2 & CDKI3 & cyclin dependent kinase 13 \\
\hline hsa-mir-16-2 & PCDHA6 & protocadherin alpha 6 \\
\hline hsa-mir-16-2 & PCDHACI & protocadherin alpha subfamily C, I \\
\hline hsa-mir-16-2 & RBM27 & RNA binding motif protein 27 \\
\hline hsa-mir-16-2 & USP49 & ubiquitin specific peptidase 49 \\
\hline hsa-mir-16-2 & SAMD9L & sterile alpha motif domain containing 9 like \\
\hline hsa-mir-16-2 & PEGIO & paternally expressed 10 \\
\hline hsa-mir-16-2 & SMARCA2 & SWI/SNF related, matrix associated, actin dependent regulator of chromatin, subfamily a, member 2 \\
\hline hsa-mir-16-2 & ZNF483 & zinc finger protein 483 \\
\hline hsa-mir-16-2 & ASTN2 & astrotactin 2 \\
\hline hsa-mir-16-2 & FOXP2 & forkhead box P2 \\
\hline hsa-mir-16-2 & CALU & calumenin \\
\hline hsa-mir-16-2 & NUP205 & nucleoporin 205 \\
\hline hsa-mir-16-2 & TMEMI78B & transmembrane protein I78B \\
\hline hsa-mir-16-2 & DCAF4L2 & DDBI and CUL4 associated factor 4 like 2 \\
\hline hsa-mir-16-2 & FBX032 & F-box protein 32 \\
\hline hsa-mir-16-2 & KBTBD3 & kelch repeat and BTB domain containing 3 \\
\hline hsa-mir-I6-2 & $M A B 2 I L I$ & mab-2I like I \\
\hline hsa-mir-16-2 & RGCC & regulator of cell cycle \\
\hline hsa-mir-16-2 & NALCN & sodium leak channel, non-selective \\
\hline hsa-mir-16-2 & TEX30 & testis expressed 30 \\
\hline hsa-mir-16-2 & RASSF8 & Ras association domain family member 8 \\
\hline hsa-mir-16-2 & $\mathrm{CI} 20 \mathrm{RF} 66$ & chromosome 12 open reading frame 66 \\
\hline hsa-mir-16-2 & DYRK2 & dual specificity tyrosine phosphorylation regulated kinase 2 \\
\hline hsa-mir-16-2 & TRPM7 & transient receptor potential cation channel subfamily M member 7 \\
\hline hsa-mir-16-2 & WDR72 & WD repeat domain 72 \\
\hline hsa-mir-l6-2 & IREB2 & iron responsive element binding protein 2 \\
\hline hsa-mir-16-2 & ZNF790 & zinc finger protein 790 \\
\hline hsa-mir-l6-2 & ZNF558 & zinc finger protein 558 \\
\hline
\end{tabular}

The microRNA hsa-mir-16-2 plays a tumor suppressor role by inducing cell cycle arrest, DNA damage repair, and apoptosis. ${ }^{33-35}$ Of the three microRNAs, hsa-mir-31 is the most studied. Previous studies show that hsa-mir-31 is a major contributor to breast cancer progression and metastasis by regulating metastasis-related genes, including RhoA, Radexin, ${ }^{36}$ WAVE3, ${ }^{37}$ RDX, SATB2, ${ }^{38,39}$ FOXP $3,{ }^{40}$ GNA13, ${ }^{41}$ and several integrin subunits, ${ }^{42}$ all involved in key steps in the invasion-metastasis cascade. In addition, hsa-mir-31 expression level is high in early-stage breast cancer tissues, diminishes as the tumor progresses to more advanced stages, and is even sometimes undetectable in metastatic tumors. ${ }^{36,37}$ Loss of hsa-mir-31 expression is accompanied by increased expression of its target genes, allowing the tumor to become more invasive and ultimately metastasize. ${ }^{37}$ In summary, these three microRNAs are involved in chemoresistance, cell cycle arrest, and metastasis, and therefore, they can theoretically predict the prognosis of breast cancer.

Of note, our analysis indicates that our prognostic signature performed especially well in young patients (age $\leq 45$ years) with basal-like breast carcinoma. To our knowledge, 
Table 7 Gene Ontology annotation analysis

\begin{tabular}{|c|c|c|c|c|c|}
\hline MicroRNA & Category & ID & Term & $P$-value & Fold enrichment \\
\hline \multirow[t]{26}{*}{ hsa-mir-16-2 } & \multirow[t]{19}{*}{ Biological process } & GO:0032774 & RNA biosynthetic process & $3.3 \mathrm{IE}-02$ & 1.82 \\
\hline & & GO:0010556 & Regulation of macromolecule biosynthetic process & $4.3 \mathrm{IE}-05$ & 1.77 \\
\hline & & GO:2000II 2 & Regulation of cellular macromolecule biosynthetic process & $2.76 \mathrm{E}-04$ & 1.74 \\
\hline & & GO:005I252 & Regulation of RNA metabolic process & $8.69 \mathrm{E}-04$ & 1.73 \\
\hline & & GO:1903506 & Regulation of nucleic acid-templated transcription & $3.70 \mathrm{E}-03$ & 1.72 \\
\hline & & GO:200II4I & Regulation of RNA biosynthetic process & 4.09E-03 & 1.71 \\
\hline & & GO:0006355 & Regulation of transcription, DNA-templated & $5.83 \mathrm{E}-03$ & 1.71 \\
\hline & & GO:0009889 & Regulation of biosynthetic process & $2.13 \mathrm{E}-04$ & 1.7 \\
\hline & & GO:0019219 & $\begin{array}{l}\text { Regulation of nucleobase-containing compound metabolic } \\
\text { process }\end{array}$ & 7.37E-04 & 1.69 \\
\hline & & GO:0031326 & Regulation of cellular biosynthetic process & $4.32 \mathrm{E}-04$ & 1.69 \\
\hline & & GO:0048523 & Negative regulation of cellular process & $6.20 \mathrm{E}-04$ & 1.68 \\
\hline & & GO:00485I9 & Negative regulation of biological process & I.52E-03 & 1.61 \\
\hline & & GO:005II7I & Regulation of nitrogen compound metabolic process & $1.02 \mathrm{E}-04$ & 1.58 \\
\hline & & GO:0060255 & Regulation of macromolecule metabolic process & $7.20 \mathrm{E}-05$ & 1.57 \\
\hline & & GO:00I0468 & Regulation of gene expression & 2.39E-02 & 1.57 \\
\hline & & GO:0080090 & Regulation of primary metabolic process & I.22E-04 & 1.57 \\
\hline & & GO:003। 323 & Regulation of cellular metabolic process & 2.27E-04 & 1.55 \\
\hline & & GO:0048856 & Anatomical structure development & $3.73 \mathrm{E}-02$ & 1.51 \\
\hline & & GO:0019222 & Regulation of metabolic process & 7.13E-04 & 1.5 \\
\hline & Cellular component & GO:0005634 & Nucleus & 4.54E-06 & 1.52 \\
\hline & \multirow[t]{6}{*}{ Molecular function } & GO:0003700 & Transcription factor activity, sequence-specific DNA binding & I.IIE-02 & 2.29 \\
\hline & & GO:000I07I & Nucleic acid binding transcription factor activity & $1.13 \mathrm{E}-02$ & 2.29 \\
\hline & & GO:0003677 & DNA binding & I.48E-02 & 1.83 \\
\hline & & GO:0046872 & Metal ion binding & I.88E-05 & 1.77 \\
\hline & & GO:0043169 & Cation binding & $5.4 \mathrm{IE}-05$ & 1.73 \\
\hline & & GO:0043167 & lon binding & $5.96 \mathrm{E}-04$ & 1.51 \\
\hline \multirow[t]{11}{*}{ hsa-mir-3I } & \multirow[t]{11}{*}{ Biological process } & GO:0042325 & Regulation of phosphorylation & 4.93E-02 & 2.57 \\
\hline & & GO:003। 325 & Positive regulation of cellular metabolic process & 7.67E-03 & 2.07 \\
\hline & & GO:005II73 & Positive regulation of nitrogen compound metabolic process & 4.79E-02 & 2.01 \\
\hline & & GO:0009893 & Positive regulation of metabolic process & 2.07E-02 & 1.98 \\
\hline & & GO:0048522 & Positive regulation of cellular process & $3.44 \mathrm{E}-05$ & 1.93 \\
\hline & & GO:00485I8 & Positive regulation of biological process & $2.12 \mathrm{E}-06$ & 1.92 \\
\hline & & GO:005।I7I & Regulation of nitrogen compound metabolic process & $5.65 \mathrm{E}-03$ & 1.67 \\
\hline & & GO:0060255 & Regulation of macromolecule metabolic process & $3.60 \mathrm{E}-03$ & 1.67 \\
\hline & & GO:003।323 & Regulation of cellular metabolic process & $4.80 \mathrm{E}-03$ & 1.66 \\
\hline & & GO:0080090 & Regulation of primary metabolic process & $7.25 \mathrm{E}-03$ & 1.65 \\
\hline & & GO:0019222 & Regulation of metabolic process & 4.29E-03 & 1.62 \\
\hline \multirow[t]{8}{*}{ hsa-mir-484 } & \multirow[t]{8}{*}{ Biological process } & GO:0048666 & Neuron development & $3.68 \mathrm{E}-02$ & 2.48 \\
\hline & & GO:0010557 & Positive regulation of macromolecule biosynthetic process & I.00E-03 & 2.08 \\
\hline & & GO:003I328 & Positive regulation of cellular biosynthetic process & $2.42 \mathrm{E}-03$ & 2 \\
\hline & & GO:0010628 & Positive regulation of gene expression & $3.84 \mathrm{E}-03$ & 1.99 \\
\hline & & GO:005I 254 & Positive regulation of RNA metabolic process & $4.90 \mathrm{E}-02$ & 1.98 \\
\hline & & GO:000989I & Positive regulation of biosynthetic process & $4.15 \mathrm{E}-03$ & 1.97 \\
\hline & & GO:0045935 & $\begin{array}{l}\text { Positive regulation of nucleobase-containing compound } \\
\text { metabolic process }\end{array}$ & $9.25 \mathrm{E}-03$ & 1.96 \\
\hline & & GO:0010604 & Positive regulation of macromolecule metabolic process & $4.02 \mathrm{E}-05$ & 1.84 \\
\hline
\end{tabular}


Table 7 (Continued)

\begin{tabular}{|c|c|c|c|c|c|}
\hline MicroRNA & Category & ID & Term & $P$-value & Fold enrichment \\
\hline & & GO:005II73 & Positive regulation of nitrogen compound metabolic process & $4.58 \mathrm{E}-04$ & 1.79 \\
\hline & & GO:003।325 & Positive regulation of cellular metabolic process & $2.55 \mathrm{E}-04$ & 1.79 \\
\hline & & GO:0009893 & Positive regulation of metabolic process & $8.18 \mathrm{E}-05$ & 1.78 \\
\hline & & GO:0009892 & Negative regulation of metabolic process & I.73E-03 & 1.77 \\
\hline & & GO:003। 324 & Negative regulation of cellular metabolic process & $8.96 \mathrm{E}-03$ & 1.77 \\
\hline & & GO:0010605 & Negative regulation of macromolecule metabolic process & $4.78 \mathrm{E}-02$ & 1.71 \\
\hline & & GO:0048869 & Cellular developmental process & $3.5 \mathrm{IE}-02$ & 1.57 \\
\hline & & GO:004873। & System development & $8.96 \mathrm{E}-03$ & 1.55 \\
\hline & & GO:0048523 & Negative regulation of cellular process & 5.89E-03 & 1.54 \\
\hline & & GO:0048522 & Positive regulation of cellular process & I.07E-03 & 1.54 \\
\hline & & GO:0007275 & Multicellular organism development & $2.81 \mathrm{E}-03$ & 1.53 \\
\hline & \multirow[t]{3}{*}{ Cellular component } & GO:0005667 & Transcription factor complex & 8.69E-03 & 3.49 \\
\hline & & GO:0043234 & Protein complex & $6.53 \mathrm{E}-04$ & 1.68 \\
\hline & & GO:003299I & Macromolecular complex & $3.60 \mathrm{E}-05$ & 1.56 \\
\hline & Molecular function & GO:0043565 & Sequence-specific DNA binding & I.34E-02 & 2.23 \\
\hline
\end{tabular}

Table 8 KEGG and PANTHER analyses

\begin{tabular}{|c|c|c|c|c|c|c|}
\hline MicroRNA & Term & Database & ID & $\begin{array}{l}\text { Input } \\
\text { number }\end{array}$ & $\begin{array}{l}\text { Background } \\
\text { number }\end{array}$ & $P$-value \\
\hline \multirow[t]{21}{*}{ hsa-mir-I6-2 } & Circadian rhythm & KEGG pathway & hsa047I0 & 4 & 30 & 0.000365555 \\
\hline & MAPK signaling pathway & KEGG pathway & hsa040I0 & 8 & 257 & $0.005579 \mid 27$ \\
\hline & Gap junction & KEGG pathway & hsa04540 & 4 & 88 & 0.014007203 \\
\hline & ALS & KEGG pathway & hsa050I4 & 3 & 51 & 0.017107832 \\
\hline & Progesterone-mediated oocyte maturation & KEGG pathway & hsa049/4 & 4 & 97 & 0.019095593 \\
\hline & Glycosaminoglycan biosynthesis - heparan sulfate/heparin & KEGG pathway & hsa00534 & 2 & 25 & 0.029980769 \\
\hline & Long-term potentiation & KEGG pathway & hsa04720 & 3 & 66 & 0.032404978 \\
\hline & Renal cell carcinoma & KEGG pathway & hsa052II & 3 & 69 & 0.036094866 \\
\hline & Dorsoventral axis formation & KEGG pathway & hsa04320 & 2 & 28 & 0.036434645 \\
\hline & Oocyte meiosis & KEGG pathway & hsa04II4 & 4 & 120 & 0.036784673 \\
\hline & Neurotrophin signaling pathway & KEGG pathway & hsa04722 & 4 & 122 & 0.038652503 \\
\hline & Thyroid hormone synthesis & KEGG pathway & hsa049/8 & 3 & 71 & 0.03866969 \\
\hline & Antigen processing and presentation & KEGG pathway & hsa046I2 & 3 & 71 & 0.03866969 \\
\hline & RNA degradation & KEGG pathway & hsa030I8 & 3 & 77 & 0.046937327 \\
\hline & FAS signaling pathway & PANTHER & P00020 & 3 & 31 & 0.004779418 \\
\hline & Integrin signaling pathway & PANTHER & P00034 & 6 & 166 & 0.008045548 \\
\hline & Cadherin signaling pathway & PANTHER & $\mathrm{P} 00012$ & 5 & 154 & 0.022562161 \\
\hline & FGF signaling pathway & PANTHER & P0002I & 4 & 103 & $0.02304764 \mid$ \\
\hline & $\begin{array}{l}\text { Heterotrimeric G-protein signaling pathway - Gi alpha } \\
\text { and Gs alpha-mediated pathway }\end{array}$ & PANTHER & P00026 & 5 & 157 & $0.0242|77|$ \\
\hline & Apoptosis signaling pathway & PANTHER & P00006 & 4 & 108 & 0.026693923 \\
\hline & CCKR signaling map & PANTHER & P06959 & 5 & 176 & $0.0365 \mid 4088$ \\
\hline \multirow[t]{3}{*}{ hsa-mir-3I } & $\begin{array}{l}\text { Heterotrimeric G-protein signaling pathway-Gq alpha and } \\
\text { Go alpha mediated pathway }\end{array}$ & PANTHER & P00027 & 4 & 121 & 0.037711913 \\
\hline & Hippo signaling pathway & KEGG pathway & hsa04390 & 5 & 153 & 0.00249984 \\
\hline & Oxytocin signaling pathway & KEGG pathway & hsa0492I & 5 & 160 & 0.003013067 \\
\hline
\end{tabular}

(Continued) 
Table 8 (Continued)

\begin{tabular}{|c|c|c|c|c|c|c|}
\hline MicroRNA & Term & Database & ID & $\begin{array}{l}\text { Input } \\
\text { number }\end{array}$ & $\begin{array}{l}\text { Background } \\
\text { number }\end{array}$ & $P$-value \\
\hline & Melanogenesis & KEGG pathway & hsa049I6 & 4 & 100 & 0.003392532 \\
\hline & Sphingolipid signaling pathway & KEGG pathway & hsa0407I & 4 & 123 & 0.006872453 \\
\hline & AMPK signaling pathway & KEGG pathway & hsa04I52 & 4 & 125 & 0.007255462 \\
\hline & Dopaminergic synapse & KEGG pathway & hsa04728 & 4 & 129 & 0.008063183 \\
\hline & Proteoglycans in cancer & KEGG pathway & hsa05205 & 5 & 208 & 0.008756401 \\
\hline & Ubiquitin-mediated proteolysis & KEGG pathway & hsa04I 20 & 4 & 137 & 0.009850899 \\
\hline & Wnt signaling pathway & KEGG pathway & hsa043I0 & 4 & 142 & 0.011089117 \\
\hline & Circadian rhythm & KEGG pathway & hsa047I0 & 2 & 30 & 0.015281252 \\
\hline & cGMP-PKG signaling pathway & KEGG pathway & hsa04022 & 4 & 173 & 0.021002596 \\
\hline & Axon guidance & KEGG pathway & hsa04360 & 4 & 178 & 0.022982044 \\
\hline & Calcium signaling pathway & KEGG pathway & hsa04020 & 4 & 179 & 0.023391098 \\
\hline & Glucagon signaling pathway & KEGG pathway & hsa04922 & 3 & 102 & 0.024384407 \\
\hline & T-cell receptor signaling pathway & KEGG pathway & hsa04660 & 3 & 107 & 0.02748699 \\
\hline & Insulin resistance & KEGG pathway & hsa0493I & 3 & 111 & 0.030113491 \\
\hline & Oocyte meiosis & KEGG pathway & hsa04II4 & 3 & 120 & 0.036489064 \\
\hline & Neurotrophin signaling pathway & KEGG pathway & hsa04722 & 3 & 122 & 0.037992724 \\
\hline & Vascular smooth muscle contraction & KEGG pathway & hsa04270 & 3 & 123 & 0.038756301 \\
\hline & ALS & KEGG pathway & hsa050I4 & 2 & 51 & 0.039184796 \\
\hline & Natural killer cell-mediated cytotoxicity & KEGG pathway & hsa04650 & 3 & 130 & 0.044318798 \\
\hline & Basal cell carcinoma & KEGG pathway & hsa052I7 & 2 & 55 & 0.044700392 \\
\hline & FGF signaling pathway & PANTHER & P0002I & 5 & 103 & 0.000457823 \\
\hline & EGF receptor signaling pathway & PANTHER & P000I8 & 5 & 114 & 0.000712265 \\
\hline & Angiogenesis & PANTHER & P00005 & 5 & 161 & $0.003092 \mid 45$ \\
\hline & Endothelin signaling pathway & PANTHER & P00019 & 3 & 79 & 0.012699626 \\
\hline & T-cell activation & PANTHER & P00053 & 3 & 79 & 0.012699626 \\
\hline & CCKR signaling map & PANTHER & P06959 & 4 & 176 & 0.022177133 \\
\hline & Apoptosis signaling pathway & PANTHER & P00006 & 3 & 108 & 0.028131602 \\
\hline & Alzheimer disease - presenilin pathway & PANTHER & P00004 & 3 & 112 & 0.030790107 \\
\hline & Lonotropic glutamate receptor pathway & PANTHER & P00037 & 2 & 46 & 0.03269137 \\
\hline & Wnt signaling pathway & PANTHER & P00057 & 5 & 295 & 0.032927779 \\
\hline & $\begin{array}{l}\text { Inflammation mediated by chemokine and cytokine } \\
\text { signaling pathway }\end{array}$ & PANTHER & P0003I & 4 & 202 & 0.034033451 \\
\hline & Oxytocin receptor mediated signaling pathway & PANTHER & P0439I & 2 & 55 & 0.044700392 \\
\hline & $\begin{array}{l}\text { Thyrotropin-releasing hormone receptor signaling } \\
\text { pathway }\end{array}$ & PANTHER & P04394 & 2 & 57 & 0.047559619 \\
\hline \multirow[t]{12}{*}{ hsa-mir-484 } & Wnt signaling pathway & KEGG pathway & hsa043I0 & 8 & 142 & 0.000852343 \\
\hline & HTLV-I infection & KEGG pathway & hsa05I66 & 11 & 259 & 0.000948874 \\
\hline & Cytokine-cytokine receptor interaction & KEGG pathway & hsa04060 & 11 & 265 & 0.001132924 \\
\hline & Adherens junction & KEGG pathway & hsa04520 & 5 & 74 & 0.003864995 \\
\hline & Hippo signaling pathway & KEGG pathway & hsa04390 & 7 & 153 & 0.005339916 \\
\hline & Jak-STAT signaling pathway & KEGG pathway & hsa04630 & 7 & 160 & 0.006710057 \\
\hline & Endometrial cancer & KEGG pathway & hsa052I3 & 4 & 54 & 0.00710104 \\
\hline & Hippo signaling pathway - multiple species & KEGG pathway & hsa04392 & 3 & 28 & 0.007685262 \\
\hline & Axon guidance & KEGG pathway & hsa04360 & 7 & 178 & 0.011418848 \\
\hline & VEGF signaling pathway & KEGG pathway & hsa04370 & 4 & 64 & 0.012312511 \\
\hline & CAMs & KEGG pathway & hsa045I4 & 6 & 143 & 0.014087791 \\
\hline & SNARE interactions in vesicular transport & KEGG pathway & hsa04I30 & 3 & 36 & 0.014469204 \\
\hline
\end{tabular}


Table 8 (Continued)

\begin{tabular}{|c|c|c|c|c|c|c|}
\hline MicroRNA & Term & Database & ID & $\begin{array}{l}\text { Input } \\
\text { number }\end{array}$ & $\begin{array}{l}\text { Background } \\
\text { number }\end{array}$ & $P$-value \\
\hline & PPAR signaling pathway & KEGG pathway & hsa03320 & 4 & 73 & 0.018678443 \\
\hline & Melanoma & KEGG pathway & hsa05218 & 4 & 73 & 0.018678443 \\
\hline & PI3K-Akt signaling pathway & KEGG pathway & hsa04I5I & 10 & 343 & 0.018921484 \\
\hline & Protein processing in endoplasmic reticulum & KEGG pathway & hsa04I4I & 6 & 167 & 0.027083189 \\
\hline & ECM-receptor interaction & KEGG pathway & hsa045I2 & 4 & 83 & 0.027778622 \\
\hline & RNA transport & KEGG pathway & hsa030I3 & 6 & 171 & 0.029828233 \\
\hline & $\mathrm{N}$-glycan biosynthesis & KEGG pathway & hsa005I0 & 3 & 49 & 0.030909326 \\
\hline & Hematopoietic cell lineage & KEGG pathway & hsa04640 & 4 & 86 & 0.030942 \\
\hline & Mismatch repair & KEGG pathway & hsa03430 & 2 & 23 & 0.042292382 \\
\hline & Insulin signaling pathway & KEGG pathway & hsa049I0 & 5 & $|4|$ & 0.043874311 \\
\hline & Pathways in cancer & KEGG pathway & hsa05200 & 10 & 399 & 0.044847988 \\
\hline & Acute myeloid leukemia & KEGG pathway & hsa0522I & 3 & 59 & 0.048121632 \\
\hline & Angiogenesis & PANTHER & P00005 & 7 & 161 & 0.006925275 \\
\hline & Wnt signaling pathway & PANTHER & P00057 & 10 & 295 & 0.007391165 \\
\hline & Pyrimidine metabolism & PANTHER & P0277I & 2 & 10 & 0.01040345 \\
\hline & Axon guidance mediated by netrin & PANTHER & P00009 & 3 & 32 & 0.010767727 \\
\hline & Blood coagulation & PANTHER & P000II & 3 & 38 & 0.016557181 \\
\hline & Axon guidance mediated by semaphorins & PANTHER & P00007 & 2 & 19 & 0.030634121 \\
\hline
\end{tabular}

Abbreviations: ALS, amyotrophic lateral sclerosis; AMPK, AMP-activated protein kinase; CAM, cell adhesion molecule; CCKR, cholecystokinin receptor; cGMP-PKG, cyclic guanosine monophosphate-dependent protein kinase G; ECM, extracellular matrix; EGF, epidermal growth factor; FAS, fatty acid synthase; FGF, fibroblast growth factor; HTLV-I, human T-cell lymphotropic virus I; Jak-STAT, janus kinase-STAT; KEGG, Kyoto Encyclopedia of Genes and Genomes; MAPK, mitogen-activated protein kinase; PPAR, peroxisome-proliferator-activated receptor; VEGF, vascular endothelial growth factor.

triple-negative breast cancer is characterized by the lack of hormone receptors (ER and PR) and HER2 expression, a common basal-like subtype, and a high propensity for distant site metastases..$^{43}$ Furthermore, effective targeted therapies beyond chemotherapy and radiotherapy are absent for triplenegative breast cancer, leading to poor clinical outcomes and a high mortality rate. ${ }^{44,45}$ These features make our signature even more valuable. We propose that high-risk patients, as determined by the calculations derived from our model, should be treated more aggressively and have a shorter follow-up interval.

Moreover, our experimental results also verified our signature. In the low-risk group, cell proliferative ability was inhibited, and S and G2/M phase cell counts were significantly increased, indicating that the cell cycle was arrested at the $\mathrm{G} 2 / \mathrm{M}$ phase. In the high-risk group, cell proliferative
A

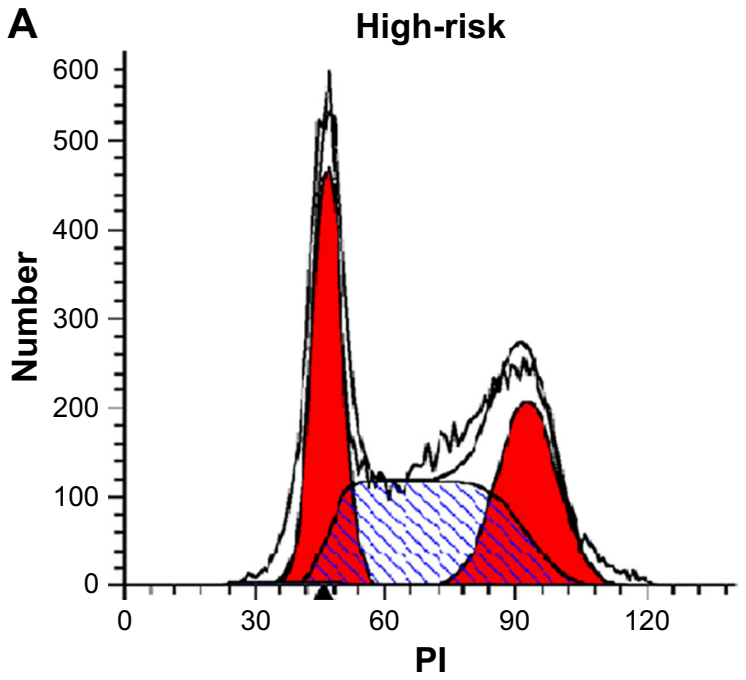

B

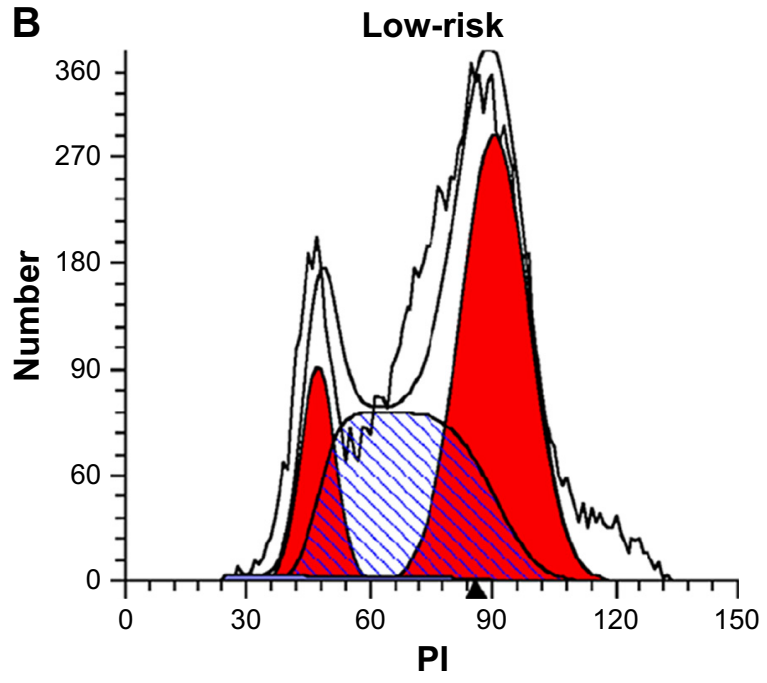

Figure 6 (Continued) 
C

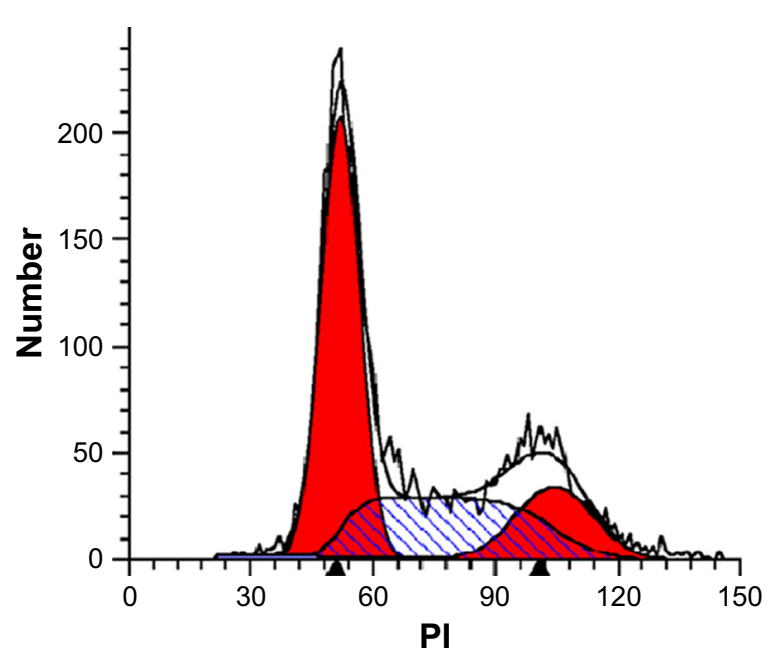

E

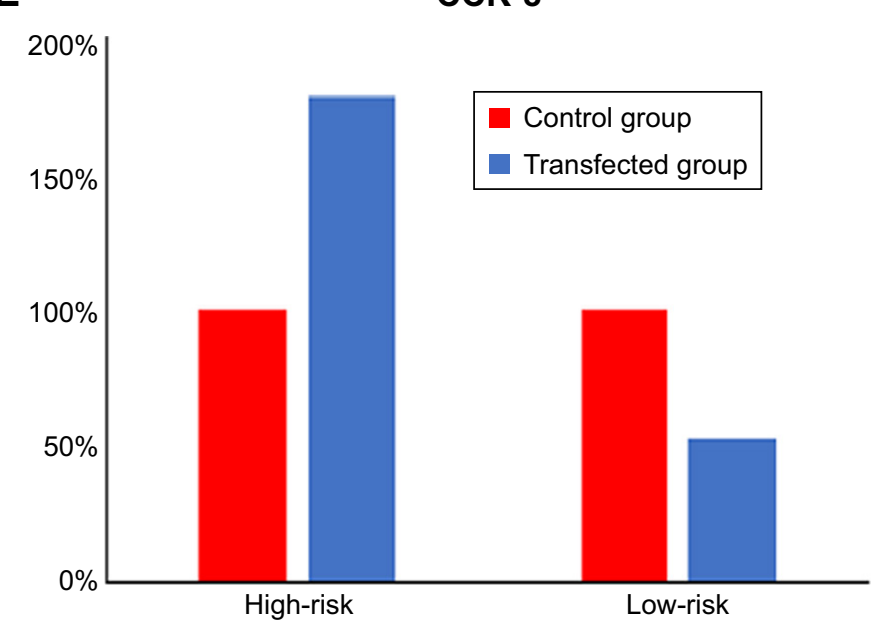

D

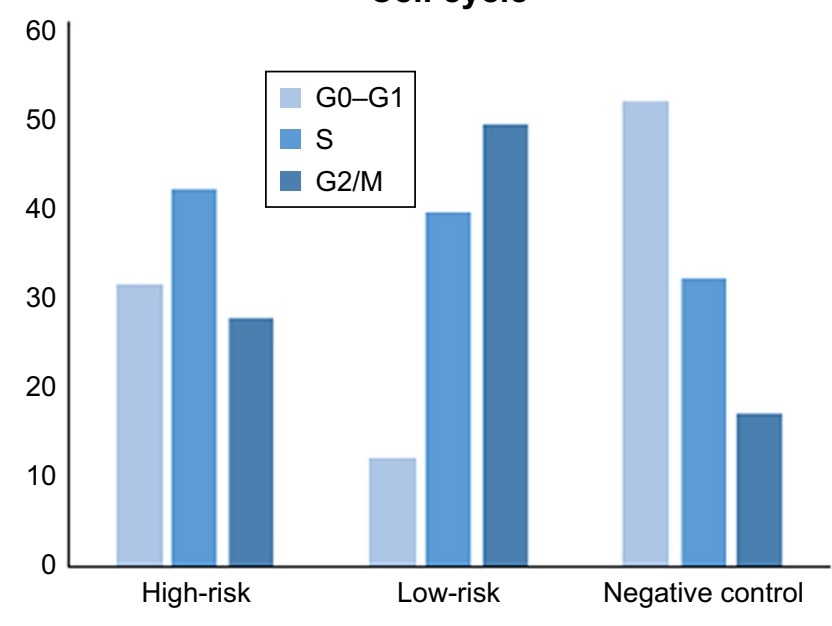

F

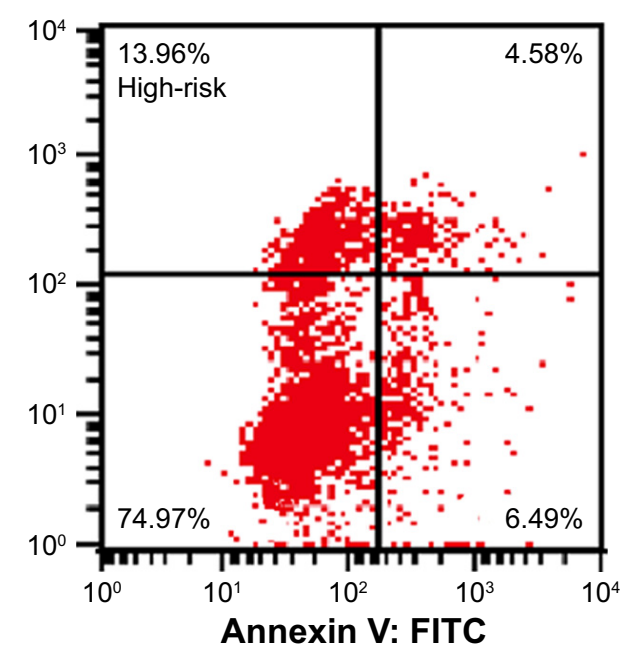

G

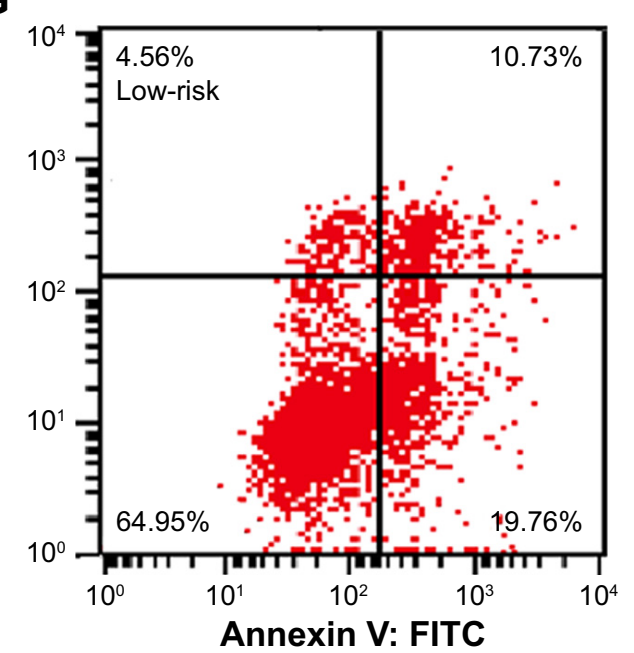

H

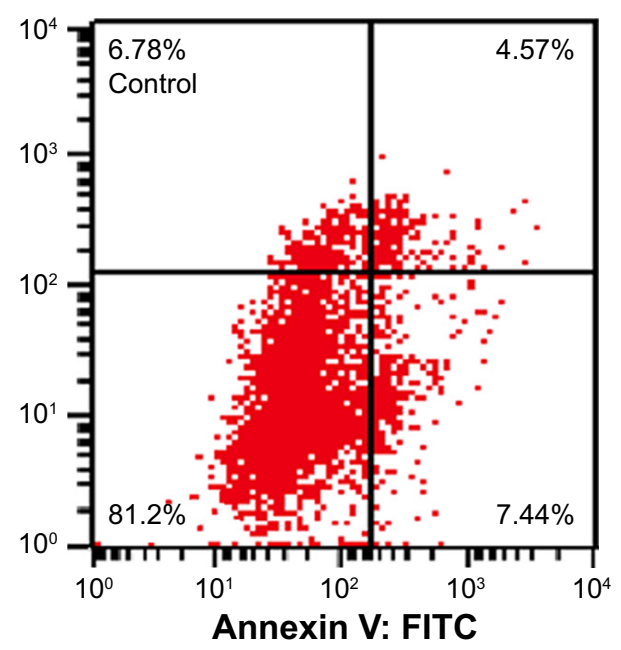

Figure 6 (A-D) Flow cytometry analysis of the cell cycle revealed that low-risk group cells were arrested at S and G2/M phase, while the cell cycle was activated in the high-risk group compared to the control group. (E) The cell viability of the high-risk group was significantly increased compared to the control group, while the viability of the low-risk group was decreased. (F-H) Flow cytometry analysis of apoptosis revealed that the apoptosis rate was II.07\% in the high-risk group, $30.49 \%$ in the low-risk group, and $12.01 \%$ in the control group.

Abbreviations: CCK-8, Cell-Counting Kit-8; FITC, fluorescein isothiocyanate; PI, propidium iodide. 
ability was significantly increased combined with low cell counts in S and G2/M phase, indicating that the cells were proliferating rapidly. We also conducted an apoptosis assay in which the cell apoptosis rate was significantly increased in the low-risk group compared to the control group. Meanwhile, there was no significant difference between the high-risk group and the control group. This was not consistent with our prediction, and we propose that perhaps this signature could not significantly affect the apoptosis of breast cancer cells. Combined together, these results suggest that our signature was associated with the viability and cell cycle of breast cancer cells.

\section{Limitations}

We must acknowledge some limitations of our study. Since we excluded patients with insufficient data for analysis (such as RNA sequencing data, histological data, and follow-up data), there could be an influence of selection bias on our final results. Despite this, our microRNA signature demonstrated performance stability. As it is well accepted that microRNAs can be secreted and/or released to the local microenvironment and into the circulation, ${ }^{46}$ it may be possible to use blood or tissue samples to detect the expression level of these three microRNAs as a reference to guide the treatment of breast cancer patients.

\section{Conclusion}

We recommend more aggressive therapy and appropriate shorter follow-up intervals for patients in the high-risk group.

\section{Availability of data and materials}

All data generated or analyzed during this study are included in this published article.

\section{Acknowledgment}

This work was supported by the National Natural Science Foundation of China: Jie Ming (grant no. 81672611) and Hui Guo (grant no. 81602350).

\section{Disclosure}

The authors report no conflicts of interest in this work.

\section{References}

1. Siegel RL, Miller KD, Jemal A. Cancer statistics, 2017. CA Cancer J Clin. 2017;67(1):7-30.

2. Parker JS, Mullins M, Cheang MC, et al. Supervised risk predictor of breast cancer based on intrinsic subtypes. J Clin Oncol. 2009;27(8): $1160-1167$.

3. Polyak K. Heterogeneity in breast cancer. J Clin Invest. 2011;121(10): 3786-3788.
4. Di Leva G, Garofalo M, Croce CM. MicroRNAs in cancer. Annu Rev Pathol. 2014;9:287-314.

5. Abba ML, Patil N, Leupold JH, et al. MicroRNAs as novel targets and tools in cancer therapy. Cancer Lett. 2017;387:84-94.

6. Bartel DP. MicroRNAs: target recognition and regulatory functions. Cell. 2009;136(2):215-233.

7. Rupaimoole R, Slack FJ. MicroRNA therapeutics: towards a new era for the management of cancer and other diseases. Nat Rev Drug Discov. 2017;16(3):203-222.

8. Mlcochova J, Faltejskova-Vychytilova P, Ferracin M, et al. MicroRNA expression profiling identifies miR-31-5p/3p as associated with time to progression in wild-type RAS metastatic colorectal cancer treated with cetuximab. Oncotarget. 2015;6(36):38695-38704.

9. Gandellini P, Giovannetti E, Nicassio F. MicroRNAs in cancer management: big challenges for small molecules. Biomed Res Int. 2015; 2015:1-2.

10. Maragkakis M, Vergoulis T, Alexiou P, et al. DIANA-microT web server upgrade supports fly and worm miRNA target prediction and bibliographic miRNA to disease association. Nucleic Acids Res. 2011; 39(Web Server issue):W145-W148.

11. Dweep H, Gretz N. miRWalk2.0: a comprehensive atlas of microRNAtarget interactions. Nat Methods. 2015;12(8):697.

12. Wong N, Wang X. miRDB: an online resource for microRNA target prediction and functional annotations. Nucleic Acids Res. 2015;43(Database issue):D146-D152.

13. Huang da W, Sherman BT, Lempicki RA. Systematic and integrative analysis of large gene Lists using David bioinformatics resources. Nat Protoc. 2009;4(1):44-57.

14. Mi H, Huang X, Muruganujan A, et al. Panther version 11: expanded annotation data from gene ontology and Reactome pathways, and data analysis tool enhancements. Nucleic Acids Res. 2017;45(D1): D183-D189.

15. Cheng H, Garrick DJ, Fernando RL. Efficient strategies for leave-oneout cross validation for genomic best linear unbiased prediction. J Anim Sci Biotechnol. 2017;8:38

16. Pan YZ, Morris ME, Yu AM. MicroRNA-328 negatively regulates the expression of breast cancer resistance protein (BCRP/ABCG2) in human cancer cells. Mol Pharmacol. 2009;75(6):1374-1379.

17. Miller TE, Ghoshal K, Ramaswamy B, et al. MicroRNA-221/222 confers tamoxifen resistance in breast cancer by targeting p27Kip1. J Biol Chem. 2008;283(44):29897-29903.

18. Sun F, Fu H, Liu Q, et al. Downregulation of CCND1 and CDK6 by miR-34a induces cell cycle arrest. FEBS Lett. 2008;582(10):1564-1568.

19. Mei M, Ren Y, Zhou X, et al. Downregulation of miR-21 enhances chemotherapeutic effect of taxol in breast carcinoma cells. Technol Cancer Res Treat. 2010;9(1):77-86.

20. Jain CK, Gupta A, Dogra N, Kumar VS, Wadhwa G, Sharma SK. MicroRNA therapeutics: the emerging anticancer strategies. Recent Pat Anticancer Drug Discov. 2014;9(3):286-296.

21. Dai X, Tan C. Combination of microRNA therapeutics with smallmolecule anticancer drugs: mechanism of action and co-delivery nanocarriers. Adv Drug Deliv Rev. 2015;81:184-197.

22. Volinia S, Croce CM. Prognostic microRNA/mRNA signature from the integrated analysis of patients with invasive breast cancer. Proc Natl Acad Sci U S A. 2013;110(18):7413-7417.

23. Buffa FM, Camps C, Winchester L, et al. microRNA-associated progression pathways and potential therapeutic targets identified by integrated mRNA and microRNA expression profiling in breast cancer. Cancer Res. 2011;71(17):5635-5645.

24. Sebolt-Leopold JS, Herrera R. Targeting the mitogen-activated protein kinase cascade to treat cancer. Nat Rev Cancer. 2004;4(12):937-947.

25. Johnson R, Halder G. The two faces of Hippo: targeting the Hippo pathway for regenerative medicine and cancer treatment. Nat Rev Drug Discov. 2014;13(1):63-79.

26. Ciardiello F, Tortora G. EGFR antagonists in cancer treatment. $N$ Engl J Med. 2008;358(11):1160-1174. 
27. Reya T, Clevers H. Wnt signalling in stem cells and cancer. Nature. 2005;434(7035):843-850.

28. Vecchione A, Belletti B, Lovat F, et al. A microRNA signature defines chemoresistance in ovarian cancer through modulation of angiogenesis. Proc Natl Acad Sci U S A. 2013;110(24):9845-9850.

29. Ye FG, Song CG, Cao ZG, et al. Cytidine deaminase axis modulated by miR-484 differentially regulates cell proliferation and chemoresistance in breast cancer. Cancer Res. 2015;75(7):1504-1515.

30. Prior C, Perez-Gracia JL, Garcia-Donas J, et al. Identification of tissue microRNAs predictive of sunitinib activity in patients with metastatic renal cell carcinoma. PLoS One. 2014;9(1):e86263.

31. Kjersem JB, Ikdahl T, Lingjaerde OC, Guren T, Tveit KM, Kure EH. Plasma microRNAs predicting clinical outcome in metastatic colorectal cancer patients receiving first-line oxaliplatin-based treatment. Mol Oncol. 2014;8(1):59-67.

32. Hu Z, Dong J, Wang LE, et al. Serum microRNA profiling and breast cancer risk: the use of miR-484/191 as endogenous controls. Carcinogenesis. 2012;33(4):828-834.

33. Lovat F, Fassan M, Gasparini P, et al. miR-15b/16-2 deletion promotes B-cell malignancies. Proc Natl Acad Sci U S A. 2015;112(37): 11636-11641.

34. Sherr CJ. The Pezcoller Lecture: cancer cell cycles revisited. Cancer Res. 2000;60(14):3689-3695.

35. Rahman M, Lovat $F$, Romano $G$, et al. miR-15b/16-2 regulates factors that promote 553 phosphorylation and augments the DNA damage response following radiation in the lung. $J$ Biol Chem. 2014;289(38): 26406-26416.

36. Valastyan S, Reinhardt F, Benaich N, et al. RETRACTED: a pleiotropically acting microRNA, miR-31, inhibits breast cancer metastasis. Cell. 2009;137(6):1032-1046.
37. Sossey-Alaoui K, Downs-Kelly E, Das M, Izem L, Tubbs R, Plow EF. WAVE3, an actin remodeling protein, is regulated by the metastasis suppressor microRNA, miR-31, during the invasion-metastasis cascade. Int J Cancer. 2011;129(6):1331-1343.

38. O'Day E, Lal A. MicroRNAs and their target gene networks in breast cancer. Breast Cancer Res. 2010;12(2):201.

39. Aprelikova O, Yu X, Palla J, et al. The role of miR-31 and its target gene SATB2 in cancer-associated fibroblasts. Cell Cycle. 2010;9(21): 4387-4398.

40. Rouas R, Fayyad-Kazan H, El Zein N, et al. Human natural Treg microRNA signature: role of microRNA-31 and microRNA-21 in FOXP3 expression. Eur J Immunol. 2009;39(6):1608-1618.

41. Rasheed SAK, Teo CR, Beillard EJ, et al. MicroRNA-31 controls G protein alpha-13 (GNA13) expression and cell invasion in breast cancer cells. Mol Cancer. 2015;14(1):67.

42. Augoff K, Das M, Bialkowska K, McCue B, Plow EF, Sossey-Alaoui K. miR-31 is a broad regulator of $\beta 1$-integrin expression and function in cancer cells. Mol Cancer Res. 2011;9(11):1500-1508.

43. Vaz-Luis I, Ottesen RA, Hughes ME, et al. Outcomes by tumor subtype and treatment pattern in women with small, node-negative breast cancer: a multi-institutional study. J Clin Oncol. 2014;32(20):2142-2150.

44. Anders C, Carey LA. Understanding and treating triple-negative breast cancer. Oncology. 2008;22(11):1233-1239, 1239-1240, 1243.

45. Carey L, Winer E, Viale G, Cameron D, Gianni L. Triple-negative breast cancer: disease entity or title of convenience? Nat Rev Clin Oncol. 2010;7(12):683-692.

46. Cortez MA, Bueso-Ramos C, Ferdin J, Lopez-Berestein G, Sood AK, Calin GA. MicroRNAs in body fluids - the mix of hormones and biomarkers. Nat Rev Clin Oncol. 2011;8(8):467-477.
OncoTargets and Therapy

\section{Publish your work in this journal}

OncoTargets and Therapy is an international, peer-reviewed, open access journal focusing on the pathological basis of all cancers, potential targets for therapy and treatment protocols employed to improve the management of cancer patients. The journal also focuses on the impact of management programs and new therapeutic agents and protocols on

\section{Dovepress}

patient perspectives such as quality of life, adherence and satisfaction The manuscript management system is completely online and includes a very quick and fair peer-review system, which is all easy to use. Visit http://www.dovepress.com/testimonials.php to read real quotes from published authors. 